\title{
Synthesis and Antiviral Activity Evaluation of some Novel Acyclic C-Nucleosides
}

\author{
Nikolaos Lougiakis, ${ }^{a}$ Panagiotis Marakos, ${ }^{a}$ Nicole Poul, ${ }^{*, a}$ and Jan Balzarini ${ }^{b}$ \\ ${ }^{a}$ Department of Pharmacy, Division of Pharmaceutical Chemistry, University of Athens; Panepistimiopolis Zografou \\ 15771, Athens, Greece: and ${ }^{b}$ Rega Institute for Medical Research; K.U.Leuven, B-3000 Leuven, Belgium. \\ Received November 2, 2007; accepted March 10, 2008; published online March 19, 2008
}

The preparation of novel 5-amino or 7-hydroxy substituted pyrazolo[4,3-b]pyridine and pyrazolo[3,4-c]pyridine acyclic $\boldsymbol{C}$-nucleosides is described. Their synthesis was carried out by condensation of suitably substituted lithiated picolines with 2-benzyloxyethoxymethylchloride followed by pyrazole ring annulation. The compounds were evaluated for their antiviral activity against a wide panel of viruses, but were found inactive at subtoxic concentrations.

Key words acyclonucleoside; pyrazolopyridine; antiviral activity

The discovery of 9-[(2-hydroxyethoxy)methyl]guanine (acyclovir, Fig. 1) ${ }^{1)}$ as the first potent and selective inhibitor of a human herpes virus ${ }^{2)}$ has stimulated continuing research into the preparation and evaluation of novel acyclic analogues of nucleosides as potential substrates of virus-specific thymidine kinase (TK) and/or inhibition of DNA polymerase after activation by the viral TK and subsequent phosphorylation by cellular enzymes to the $5^{\prime}$-triphosphates. ${ }^{3,4)}$ Structureactivity relationship studies have been explored extensively and revealed that both the nature of the heterocyclic base and the chemical structure of the aliphatic substituent have a pronounced effect on the antiviral activity of these molecules. Purine nucleosides structurally related to acyclovir that are currently used in the clinic are ganciclovir, ${ }^{5,6)}$ which is useful against cytomegalovirus (HCMV) infections and the penciclovir prodrug famciclovir," which is marketed for shingles. The antiviral spectrum of these agents is limited to the herpes virus genus. On the other hand, 3-deazaadenosine as well as a number of acyclic and carbocyclic adenosine analogues, such as the $S$ enantiomer of 9-(2,3-dihydroxypropyl)-adenine (S-DHPA), aristeromycin, neplanocin A and 3-deazaneplanocin A (Fig. 1) were found to act as reversible inhibitors of $S$-adenosyl-L-homocysteine (SAH) hydrolase. ${ }^{8)}$ These SAH hydrolase inhibitors exhibit potent antiviral activity against a number of DNA and RNA viruses, which heavily depend on methylation reactions for viral replication. More interestingly, acyclic nucleoside phosphonates have been developed, which retain marked activity against thymidine kinase deficient viral strains and some of them are useful for the treatment of HCMV, retrovirus (HIV) and human hepatitis B virus (HBV) infections. ${ }^{9)}$

In the course of our studies, concerning the preparation of a number of $C$-nucleosides structurally related to inosine and adenosine $\mathrm{e}^{10,11)}$ and in conjunction with the stimulating results

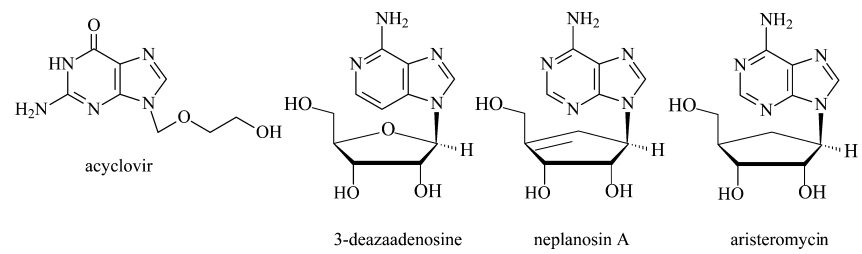

Fig. 1. Structures of Acyclovir and Adenosine Analogues reported for acyclic nucleosides, we were interested in determining whether antiviral activity is retained when the (2-hydroxyethoxy)methyl group of acyclovir is employed in combination with a base structurally related to 3-deazaadenine. Within this context we report here the synthesis and the in vitro antiviral evaluation of some new acyclic $C$-nucleoside analogues, bearing the 8-aza-1,9-dideazapurine or the 8-aza-3,9-dideazapurine skeleton.

\section{Results and Discussion}

Chemistry For the preparation of the pyrazolopyridinone 13 (Chart 1) we used commercial 2-picoline $N$-oxide (1) which was converted to the picoline 4 through known procedures. ${ }^{12)}$ Subsequent nitration of $\mathbf{4}$ provided a mixture of the isomeric nitroderivatives $\mathbf{5}$ and $\mathbf{6}$ and from this mixture only the desired compound $\mathbf{6}$ could be isolated in pure form by column chromatography, whereas $\mathbf{5}$ was contaminated with traces of $\mathbf{6}$. The isomer $\mathbf{6}$ was reduced to the aminoderivative 7 , which has been previously reported as a sideproduct of the ammonolysis of 3-methoxy-2-acylfuran. ${ }^{13)}$

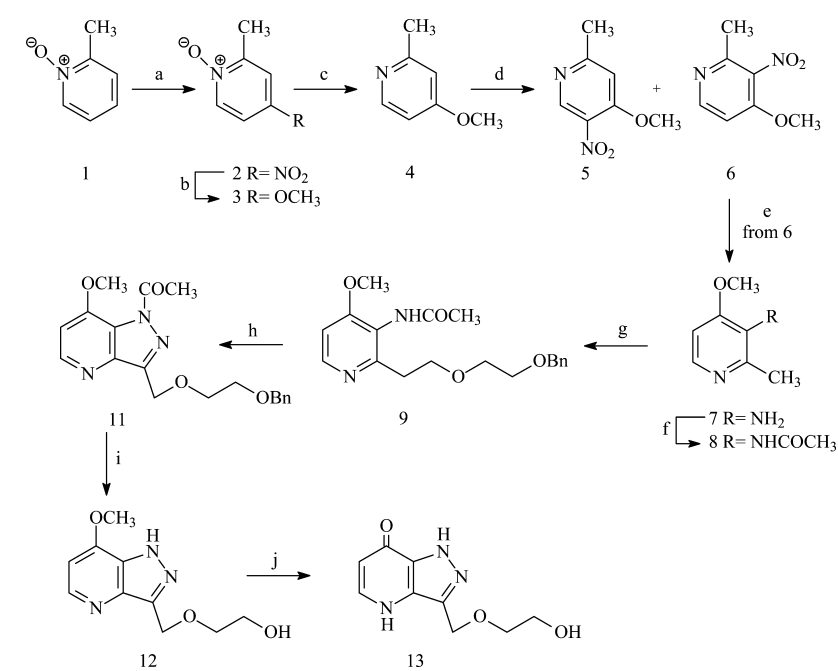

Reagents and conditions: a) $\mathrm{H}_{2} \mathrm{SO}_{4}, \mathrm{HNO}_{3}, 160^{\circ} \mathrm{C}$; b) $\mathrm{CH}_{3} \mathrm{ONa}, \mathrm{CH}_{3} \mathrm{OH}, 80^{\circ} \mathrm{C}$; c) $\mathrm{Fe}, \mathrm{CH}_{3} \mathrm{CO}_{2} \mathrm{H}, 130^{\circ} \mathrm{C}$; d) $\mathrm{H}_{2} \mathrm{SO}_{4}, \mathrm{HNO}_{3}, 65^{\circ} \mathrm{C}$; e) $\mathrm{H}_{2}, \mathrm{Pd}-\mathrm{C}, \mathrm{EtOH}$; f) $\mathrm{Ac}_{2} \mathrm{O}, \mathrm{CH}_{2} \mathrm{Cl}_{2}$, rt; g) (1) $n$-BuLi (2.5 eq), THF, $-78^{\circ} \mathrm{C}$, (2) 2-benzyloxyethoxymethylchloride, THF; h) AcOK, $\mathrm{Ac}_{2} \mathrm{O}$, isoamyle nitrite, $\mathrm{C}_{6} \mathrm{H}_{6}$, reflux; i) $\mathrm{BCl}_{3}, \mathrm{CH}_{2} \mathrm{Cl}_{2},-70^{\circ} \mathrm{C}$; j) $\mathrm{HCl}(36 \%$ ), $\mathrm{EtOH}, 80^{\circ} \mathrm{C}$.

Chart 1 
Compound 7 was then acetylated to give the acetamide $\mathbf{8}$, which was lithiated using $n$-butyllithium in THF solution. The resulting anion was reasonably stable to be trapped by 2-benzyloxyethoxymethylchloride, ${ }^{14)}$ thus allowing the preparation of the substituted pyridine 9. From this reaction we have also isolated a significant amount $(32 \%)$ of a by-product the structure of which was unambiguously assigned as 10 (Fig. 2), on the basis of 1-D and 2-D NMR data. The formation of $\mathbf{1 0}$ is due to a competitive anion formation on the acetamide's methyl group.

Compound 9 was then heated at reflux in benzene with isoamyl nitrite, in the presence of acetic anhydride. ${ }^{15)}$ This furnished the substituted 1-acetylpyrazolo[4,3-b]pyridine 11 through a rearrangement of the intermediate $N$-nitroso compound. Both the $N$-acetyl and benzyl groups were easily cleaved upon treatment of 11 with a $1 \mathrm{M}$ solution of $\mathrm{BCl}_{3}$ in hexane at low temperature. This provided the 7-methoxyderivative 12 which was then converted to the target pyrazolopyridinone by heating into an ethanolic $\mathrm{HCl}$ solution.

Following an analogous procedure, using the readily prepared acetamide 19 (Chart 2), ${ }^{16)}$ we prepared the isomeric pyrazolo[3,4-c]pyridinone $\mathbf{2 3}$ in reasonable overall yield.

In order to prepare the corresponding 5 -aminosubstituted derivatives, we used the aminonitropicoline $24^{17)}$ which was<smiles>COc1ccnc(C)c1NC(=O)CCOCC[Hg]c1ccccc1</smiles>

10

Fig. 2. Structure of the By-product $\mathbf{1 0}$
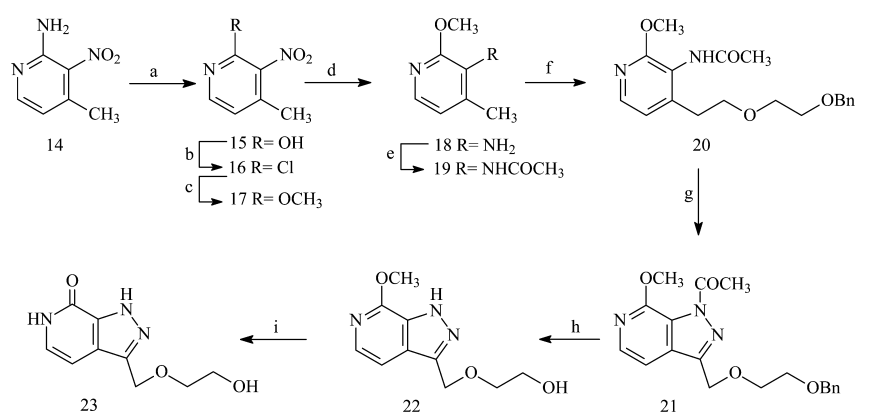

Reagents and conditions: a) $\mathrm{NaNO}_{2}, \mathrm{H}_{2} \mathrm{SO}_{4}, \mathrm{H}_{2} \mathrm{O}$; b) $\mathrm{PCl}_{5}, \mathrm{POCl}_{3}, 130^{\circ} \mathrm{C}$; c) $\mathrm{CH}_{3} \mathrm{ONa}, \mathrm{CH}_{3} \mathrm{OH}, 80^{\circ} \mathrm{C}$; d) $\mathrm{H}_{2}, \mathrm{Pd}-\mathrm{C}$, EtOH; e) $\mathrm{Ac}_{2} \mathrm{O}, \mathrm{CH}_{2} \mathrm{Cl}_{2}$, rt; f) (1) $n$-BuLi (2.5 eq), THF, $-78^{\circ} \mathrm{C}$, (2) 2-benzyloxyethoxymethylchloride, THF; g) $\mathrm{AcOK}, \mathrm{Ac}_{2} \mathrm{O}$, isoamyle nitrite, $\mathrm{C}_{6} \mathrm{H}_{6}$, reflux; h) $\mathrm{BCl}_{3}, \mathrm{CH}_{2} \mathrm{Cl}_{2},-70^{\circ} \mathrm{C}$; i) $\mathrm{HCl} / \mathrm{CH}_{3} \mathrm{OH}$, rt.

Chart 2 first converted to the Boc-protected analogue $\mathbf{2 5}$ and then, upon reduction, to the acetamide 27 (Chart 3). The Bocprotecting group is suitable in terms of its stability to anionic reaction conditions. Thus, lithiation of 27 with $3.3 \mathrm{eq}$ of $n$-butyllithium followed by treatment with 2-benzyloxyethoxymethylchloride provided the intermediate pyridine 28, which was subjected to ring-closure according to the afore-mentioned conditions to result in the pyrazolopyridine 29. The Boc-group was then easily cleaved by the use of trifluoracetic acid and the resulting pyrazolopyridine $\mathbf{3 0}$ was converted to the target compound $\mathbf{3 1}$ upon treatment with boron trichloride in dichloromethane solution.

The application of this strategy using the isomeric picoline 33 (Chart 4) which was prepared from the previously reported amino-derivative $32,{ }^{18)}$ resulted in six steps in the 3-substituted 5-aminopyrazolopyridine 39.

Antiviral and Cytostatic Evaluations The cytotoxicity and antiviral activity of compounds against the replication of Herpes simplex virus-1 (KOS), Herpes simplex virus-2 (G), Vaccinia virus, Vesicular stomatitis virus and Herpes simplex virus-1 ACVr in HEL cell cultures, against the replication of Vesicular stomatitis virus, Coxsackie virus B4, Respiratory syncytial virus in HeLa cell cultures, against the replication of Para-influenza-3 virus, Reovirus-1, Sindbis virus, Coxsackie virus B4, Punta Toro virus in Vero cell cultures, against the replication of Feline Corona virus and Human Corona (SARS) virus in feline kidney Crandel cell cultures and against HIV-1- and HIV-2-induced cytopathicity in CEM cell cultures were evaluated. The compounds were antivirally inactive at subtoxic concentrations.

The inhibitory effects of the compounds on the proliferation of murine leukemia cells (L1210) and human T-lympho-

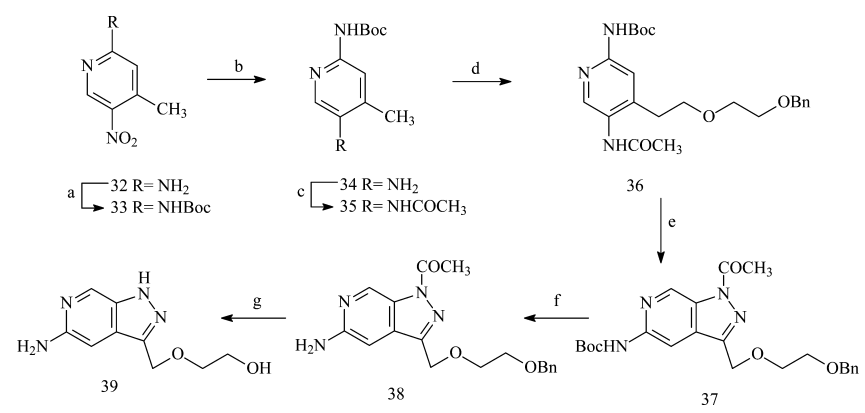

Reagents and conditions: a) (1) $\mathrm{NaH}, \mathrm{THF}, 0^{\circ} \mathrm{C}$, (2) $\mathrm{Boc}_{2} \mathrm{O}$, THF; b) $\mathrm{H}_{2}, \mathrm{Pd}-\mathrm{C}$ EtOH; c) $\mathrm{Ac}_{2} \mathrm{O}, \mathrm{CH}_{2} \mathrm{Cl}_{2}$, r.t.; d) (1) $n$-BuLi (3.3 eq), THF, $-78^{\circ} \mathrm{C}$, (2) 2-benzyloxyethoxymethylchloride, THF; e) $\mathrm{AcOK}, \mathrm{Ac}_{2} \mathrm{O}$, isoamyle nitrite, benzene, reflux; $\mathrm{f}$ ) $\left.\mathrm{CF}_{3} \mathrm{CO}_{2} \mathrm{H}, \mathrm{CH}_{2} \mathrm{Cl}_{2}, \mathrm{rt} ; \mathrm{g}\right) \mathrm{BCl}_{3}, \mathrm{CH}_{2} \mathrm{Cl}_{2},-70^{\circ} \mathrm{C}$.

Chart 4

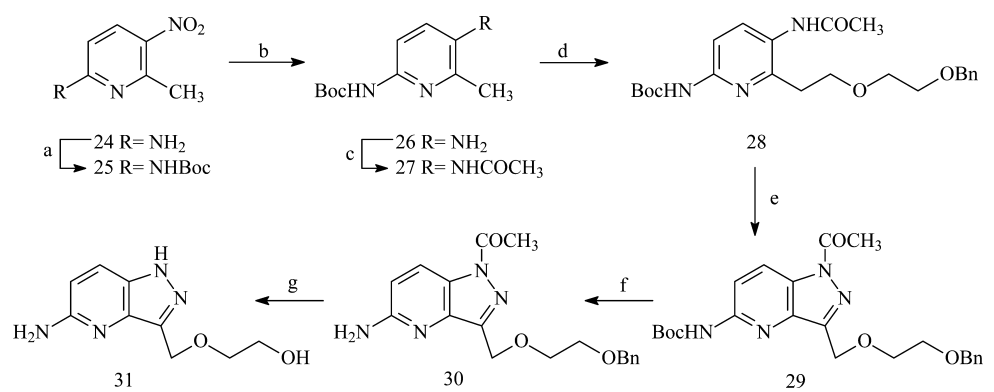

Reagents and conditions: a) (1) $\mathrm{NaH}, \mathrm{THF}, 0{ }^{\circ} \mathrm{C}$, (2) $\mathrm{Boc}_{2} \mathrm{O}$, THF; b) $\mathrm{H}_{2}, \mathrm{Pd}-\mathrm{C}, \mathrm{EtOH}$; c) $\mathrm{Ac}_{2} \mathrm{O}, \mathrm{CH}_{2} \mathrm{Cl}_{2}, \mathrm{rt}$; d) (1) $n$ - $\mathrm{BuLi}\left(3.3\right.$ eq), THF, $-78^{\circ} \mathrm{C}$, (2) 2-benzyloxyethoxymethylchloride, THF; e) $\mathrm{AcOK}, \mathrm{Ac}_{2} \mathrm{O}$, isoamyle nitrite, benzene, reflux; f) $\left.\mathrm{CF}_{3} \mathrm{CO}_{2} \mathrm{H}, \mathrm{CH}_{2} \mathrm{Cl}_{2}, \mathrm{rt}^{2} \mathrm{~g}\right) \mathrm{BCl}_{3}, \mathrm{CH}_{2} \mathrm{Cl}_{2},-70{ }^{\circ} \mathrm{C}$. 
cyte cells (Molt4/C8, CEM) were also determined. Only compound 13 exhibited a slight antiproliferative activity with $\mathrm{IC}_{50}$ values within the range of $126-220 \mu \mathrm{M}$ against the tested cell lines.

The inactivity of the new compounds is likely due to their inability to be phosphorylated to a potentially active metabolite and to the lack of being efficient substrates for viral enzymes. It seems that a closer similarity of the purine-like nucleus to guanine should be taken under consideration, since the replacement of the imidazole ring of the purine skeleton by the isosteric pyrazole nucleus and the lack of the suitable second substituent on the pyridine ring, are not in favour of the antiviral activity of this class of compounds.

\section{Experimental}

All chemicals were purchased from Aldrich Chemical Co. Melting points were determined on a Büchi apparatus and are uncorrected. Flash chromatography was performed on Merck silica gel $60(0.040-0.063 \mathrm{~mm})$. Analytical thin layer chromatography (TLC) was carried out on precoated $(0.25 \mathrm{~mm})$ Merck silica gel F-254 plates. ${ }^{1} \mathrm{H}-\mathrm{NMR}$ spectra and 2D spectra were recorded on a Bruker Avanche 400 instrument, whereas ${ }^{13} \mathrm{C}-\mathrm{NMR}$ spectra were recorded on a Bruker AC 200 spectrometer in deuterated solvents and were referenced to TMS ( $\delta$ scale). The signals of ${ }^{1} \mathrm{H}$ and ${ }^{13} \mathrm{C}$ spectra were unambiguously assigned by using $2 \mathrm{D}$ NMR techniques: ${ }^{1} \mathrm{H}-{ }^{1} \mathrm{H}$ COSY, NOESY HMQC and HMBC. Elemental analyses were performed on a Perkin-Elmer PE 240C Elemental Analyzer (Norwalk, CT, U.S.A.) and were within $\pm 0.4 \%$ of the theoretical values. The oily analytical samples, upon the appropriate chromatographic purification were dried in vacuo (vacuum pump) at $90^{\circ} \mathrm{C}$ in the presence of phosphorous pentoxide for $12 \mathrm{~h}$.

4-Methoxy-2-methyl-3-nitropyridine (6) A mixture of sulfuric acid $(98 \%, 1.6 \mathrm{ml})$ and nitric acid $(65 \%, 1.6 \mathrm{ml})$ was added at $0{ }^{\circ} \mathrm{C}$ to a solution of $\mathbf{4}^{12)}(2.4 \mathrm{~g}, 19.51 \mathrm{mmol})$ in sulfuric acid $(98 \%, 11.1 \mathrm{ml})$ and the resulting solution was heated at $65^{\circ} \mathrm{C}$ for $12 \mathrm{~h}$. The mixture was then poured into ice-water, neutralized with a $40 \% \mathrm{NaOH}$ solution and the precipitate was filtered and air-dried. Flash chromatography of the residue, on silica gel, using a mixture of $\mathrm{CH}_{2} \mathrm{Cl}_{2} / \mathrm{EtOAc}(85 / 15, \mathrm{v} / \mathrm{v})$ as the eluent, provided pure only the title nitrocompound $\mathbf{6}$ in $48 \%$ yield, whereas the isomeric nitroderivative 5 was eluted in mixture with 6. $\mathrm{mp}$ : $55-56^{\circ} \mathrm{C}$ (EtOAc$n$-hexane). ${ }^{1} \mathrm{H}-\mathrm{NMR}\left(400 \mathrm{MHz}, \mathrm{CDCl}_{3}\right) \delta: 2.52\left(3 \mathrm{H}, \mathrm{s}, \mathrm{CH}_{3}\right), 3.95(3 \mathrm{H}, \mathrm{s}$, $\left.\mathrm{OCH}_{3}\right), 6.85(1 \mathrm{H}, \mathrm{d}, J=5.8 \mathrm{~Hz}, \mathrm{H}-5), 8.45(1 \mathrm{H}, \mathrm{d}, J=5.8 \mathrm{~Hz}, \mathrm{H}-6) .{ }^{13} \mathrm{C}-\mathrm{NMR}$ $\left(50 \mathrm{MHz}, \mathrm{CDCl}_{3}\right) \delta: 20.37\left(\mathrm{CH}_{3}\right), 56.64\left(\mathrm{CH}_{3} \mathrm{O}\right), 105.93(\mathrm{C}-5), 138.80(\mathrm{C}-$ 3), $151.42(\mathrm{C}-2), 151.70(\mathrm{C}-6), 157.30(\mathrm{C}-4)$.

$\mathrm{N}$-(4-Methoxy-2-methylpyridin-3-yl)acetamide (8) To a solution of the amine $7(1.1 \mathrm{~g}, 7.97 \mathrm{mmol})$ in dry $\mathrm{CH}_{2} \mathrm{Cl}_{2}(25 \mathrm{ml})$ was added acetic anhydride $(0.95 \mathrm{ml}, 10 \mathrm{mmol})$ and the mixture was stirred at room temperature for $10 \mathrm{~h}$. The solvent was then vacuum-evaporated and the residue was purified by column chromatography (silica gel) using a mixture of $\mathrm{CH}_{2} \mathrm{Cl}_{2}$ / $\mathrm{CH}_{3} \mathrm{OH}(98 / 2, \mathrm{v} / \mathrm{v})$ as the eluent, to give pure $8(1.32 \mathrm{~g}, 92 \%) . \mathrm{mp}: 136^{\circ} \mathrm{C}$ (EtOH). ${ }^{1} \mathrm{H}-\mathrm{NMR}\left(400 \mathrm{MHz}, \mathrm{CDCl}_{3}\right) \delta: 2.15\left(3 \mathrm{H}, \mathrm{s}, \mathrm{COCH}_{3}\right), 2.37(3 \mathrm{H}, \mathrm{s}$, $\left.\mathrm{CH}_{3}\right), 3.79\left(3 \mathrm{H}, \mathrm{s}, \mathrm{OCH}_{3}\right), 6.65(1 \mathrm{H}, \mathrm{d}, J=5.7 \mathrm{~Hz}, \mathrm{H}-5), 7.47\left(1 \mathrm{H}, \mathrm{br} \mathrm{s}, \mathrm{D}_{2} \mathrm{O}\right.$ exchang., $\mathrm{NH}), 8.23(1 \mathrm{H}, \mathrm{d}, J=5.7 \mathrm{~Hz}, \mathrm{H}-6) .{ }^{13} \mathrm{C}-\mathrm{NMR}\left(50 \mathrm{MHz}, \mathrm{CDCl}_{3}\right) \delta$ : $21.10\left(\mathrm{CH}_{3}\right), 23.34\left(\mathrm{CH}_{3} \mathrm{CO}\right), 55.78\left(\mathrm{CH}_{3} \mathrm{O}\right), 104.67(\mathrm{C}-5), 120.83(\mathrm{C}-3)$, 148.52 (C-6), 156.88 (C-2), 160.54 (C-4), $169.12\left(\mathrm{CH}_{3} \mathrm{CO}\right)$. Anal. Calcd for $\mathrm{C}_{9} \mathrm{H}_{12} \mathrm{~N}_{2} \mathrm{O}_{2}: \mathrm{C}, 59.99 ; \mathrm{H}, 6.71 ; \mathrm{N}, 15.55$. Found: $\mathrm{C}, 60.12 ; \mathrm{H}, 6.55 ; \mathrm{N}, 15.43$.

$\boldsymbol{N}$-[2-(2-Benzyloxyethoxy)ethyl-4-methoxypyridin-3-yl]acetamide (9) To a solution of the picoline $8(0.6 \mathrm{~g}, 3.33 \mathrm{mmol})$ in dry THF $(30 \mathrm{ml})$ at $-78^{\circ} \mathrm{C}$ was added under argon $n$-BuLi $(5.2 \mathrm{ml}, 8.32 \mathrm{mmol}, 1.6 \mathrm{M}$ solution in hexanes). The resulting light yellow solution was stirred at $-78^{\circ} \mathrm{C}$ for $15 \mathrm{~min}$ and the temperature then raised to $-50^{\circ} \mathrm{C}$ for $50 \mathrm{~min}$. The orangecolored solution was cooled to $-78^{\circ} \mathrm{C}$ and a solution of 2-benzyloxyethoxymethylchloride $\left.^{14}\right)(0.86 \mathrm{~g}, 4.29 \mathrm{mmol})$ in dry THF $(5 \mathrm{ml})$ was added dropwise. The resulting mixture was stirred at $-78^{\circ} \mathrm{C}$ for $15 \mathrm{~min}$ and the temperature was then allowed to rise to the ambient one. A saturated ammonium chloride solution was then added to the reaction mixture to quench the excess $n$-BuLi. The solvent was vacuum-evaporated, water was added to the residue and this was extracted with $\mathrm{CH}_{2} \mathrm{Cl}_{2}$. The organic extracts were dried $\left(\mathrm{Na}_{2} \mathrm{SO}_{4}\right)$ and concentrated to dryness to give an oil which was purified by flash chromatography (silica gel) using EtOAc as the eluent, to give compounds 9 and $\mathbf{1 0}$.

Data for 9: Yield: $40 \%$. Oil. ${ }^{1} \mathrm{H}-\mathrm{NMR}\left(400 \mathrm{MHz}, \mathrm{CDCl}_{3}\right) \delta: 2.01(3 \mathrm{H}, \mathrm{s}$, $\left.\mathrm{COCH}_{3}\right), 3.01\left(2 \mathrm{H}, \mathrm{t}, J=5.5 \mathrm{~Hz}, \mathrm{PyrCH}_{2} \mathrm{CH}_{2} \mathrm{O}\right), 3.58-3.60(4 \mathrm{H}, \mathrm{m}$,
$\left.\mathrm{OCH}_{2} \mathrm{CH}_{2} \mathrm{O}\right), 3.81\left(2 \mathrm{H}, \mathrm{t}, J=5.5 \mathrm{~Hz}, \mathrm{PyrCH}_{2} \mathrm{CH}_{2} \mathrm{O}\right), 3.84\left(3 \mathrm{H}, \mathrm{s}, \mathrm{OCH}_{3}\right)$, $4.51\left(2 \mathrm{H}, \mathrm{s}, \mathrm{CH}_{2} \mathrm{Ph}\right), 6.74(1 \mathrm{H}, \mathrm{d}, J=5.7 \mathrm{~Hz}, \mathrm{H}-5), 7.27-7.33(5 \mathrm{H}, \mathrm{m}, \mathrm{Ph}-$ $\mathrm{H}), 8.16\left(1 \mathrm{H}\right.$, br s, $\mathrm{D}_{2} \mathrm{O}$ exchang., $\left.\mathrm{NH}\right), 8.31(1 \mathrm{H}, \mathrm{d}, J=5.7 \mathrm{~Hz}, \mathrm{H}-6) .{ }^{13} \mathrm{C}-$ NMR $\left(50 \mathrm{MHz}, \mathrm{CDCl}_{3}\right) \delta: 23.10\left(\underline{\mathrm{CH}}_{3} \mathrm{CO}\right), 35.06\left(\mathrm{Pyr}_{\mathrm{CH}} \mathrm{CH}_{2} \mathrm{O}\right), 55.86$ $\left(\mathrm{CH}_{3} \mathrm{O}\right), 69.48\left(\mathrm{OCH}_{2} \mathrm{CH}_{2} \mathrm{O}\right), 69.94\left(\mathrm{OCH}_{2} \mathrm{CH}_{2} \mathrm{O}\right), 71.59\left(\mathrm{PyrCH}_{2} \mathrm{CH}_{2} \mathrm{O}\right)$ $73.41\left(\mathrm{CH}_{2} \mathrm{Ph}\right), 105.72(\mathrm{C}-5), 122.23(\mathrm{C}-3), 127.62\left(\mathrm{C}-4^{\prime}\right), 127.97(2 \times$ Phenyl C), 128.52 ( $2 \times$ Phenyl C), 137.69 (C-1'), 149.05 (C-6), 157.34 (C-2), 161.41 (C-4), $169.18\left(\mathrm{CH}_{3} \mathrm{CO}\right)$. Anal. Calcd for $\mathrm{C}_{19} \mathrm{H}_{24} \mathrm{~N}_{2} \mathrm{O}_{4}: \mathrm{C}, 66.22 ; \mathrm{H}$, $7.02 ; \mathrm{N}, 8.13$. Found: C, 66.03; H, 6.91; N, 8.07.

Data for 3-[3-(2-Benzyloxyethoxy)-1-oxopropanamine]-4-methoxy-2methylpyridine (10): Yield: $32 \%$. Oil. ${ }^{1} \mathrm{H}-\mathrm{NMR}\left(400 \mathrm{MHz}, \mathrm{CDCl}_{3}\right) \delta: 2.38$ $\left(3 \mathrm{H}, \mathrm{s}, \mathrm{CH}_{3}\right), 2.67\left(2 \mathrm{H}, \mathrm{t}, J=5.7 \mathrm{~Hz}, \mathrm{NH}(\mathrm{O}=) \mathrm{CCH}_{2} \mathrm{CH}_{2} \mathrm{O}\right), 3.64-3.66(2 \mathrm{H}$, $\left.\mathrm{m}, \mathrm{OCH}_{2} \mathrm{CH}_{2} \mathrm{O}\right), 3.71-3.73\left(2 \mathrm{H}, \mathrm{m}, \mathrm{OCH}_{2} \mathrm{CH}_{2} \mathrm{O}\right), 3.76\left(3 \mathrm{H}, \mathrm{s}, \mathrm{OCH}_{3}\right), 3.85$ $\left(2 \mathrm{H}, \mathrm{t}, J=5.7 \mathrm{~Hz}, \mathrm{NH}(\mathrm{O}=) \mathrm{CCH}_{2} \mathrm{CH}_{2} \mathrm{O}\right), 4.47\left(2 \mathrm{H}, \mathrm{s}, \mathrm{CH}_{2} \mathrm{Ph}\right), 6.63(1 \mathrm{H}, \mathrm{d}$, $J=5.7 \mathrm{~Hz}, \mathrm{H}-5), 7.17-7.24(5 \mathrm{H}, \mathrm{m}, \mathrm{Ph}-\mathrm{H}), 8.05\left(1 \mathrm{H}\right.$, br s, $\mathrm{D}_{2} \mathrm{O}$ exchang., $\mathrm{NH}), 8.26(1 \mathrm{H}, \mathrm{d}, J=5.7 \mathrm{~Hz}, \mathrm{H}-6) .{ }^{13} \mathrm{C}-\mathrm{NMR}\left(50 \mathrm{MHz}, \mathrm{CDCl}_{3}\right) \delta: 21.19$ $\left(\mathrm{NHCOCH}_{2}\right), 37.13\left(\mathrm{PyrCH}_{3}\right), 55.72\left(\mathrm{CH}_{3} \mathrm{O}\right), 67.31\left(\mathrm{COCH}_{2} \mathrm{CH}_{2} \mathrm{O}\right), 69.15$ $\left(\mathrm{OCH}_{2} \mathrm{CH}_{2} \mathrm{O}\right), 70.40\left(\mathrm{OCH}_{2} \underline{\mathrm{CH}}_{2} \mathrm{O}\right), 73.35\left(\mathrm{CH}_{2} \mathrm{Ph}\right), 104.69(\mathrm{C}-5), 120.79$ (C-3), 127.77 (C-4'), 127.93 (2×Phenyl C), 128.41 (2×Phenyl C), 137.76 (C-1'), 148.57 (C-6), 156.78 (C-2), 160.54 (C-4), 170.59 ( $\mathrm{CH}_{3}$ CO). Anal. Calcd for $\mathrm{C}_{19} \mathrm{H}_{24} \mathrm{~N}_{2} \mathrm{O}_{4}$ : C, 66.22; H, 7.02; N, 8.13. Found: C, 65.94; H, 7.17; N, 8.32

1-Acetyl-3-(2-benzyloxyethoxy)methyl-7-methoxy-1 H-pyrazolo[4,3b]pyridine (11) Potassium acetate $(23 \mathrm{mg}, 0.233 \mathrm{mmol})$ and acetic anhydride $(0.07 \mathrm{ml}, 0.74 \mathrm{mmol})$ were added to a solution of $9(70 \mathrm{mg}, 0.20 \mathrm{mmol})$ in dry benzene $(20 \mathrm{ml})$ under Ar. The reaction mixture was heated at reflux, isoamyl nitrite $(0.06 \mathrm{ml}, 0.44 \mathrm{mmol})$ was added and the resulting mixture was refluxed for $7 \mathrm{~h}$. The insoluble material was then filtered off, the solvent was vacuum-evaporated and the residue was purified by column chromatography (silica gel) using a mixture of cyclohexane/EtOAc $(7 / 3, v / v)$ as the eluent, to give $11(65 \mathrm{mg}, 87 \%)$ as an oil. ${ }^{1} \mathrm{H}-\mathrm{NMR}\left(400 \mathrm{MHz}, \mathrm{CDCl}_{3}\right) \delta$. $2.81\left(3 \mathrm{H}, \mathrm{s}, \mathrm{COCH}_{3}\right), 3.70\left(2 \mathrm{H}, \mathrm{t}, J=4.7 \mathrm{~Hz}, \mathrm{OCH}_{2} \mathrm{CH}_{2} \mathrm{OBn}\right), 3.87(2 \mathrm{H}, \mathrm{t}$, $\left.J=4.7 \mathrm{~Hz}, \mathrm{OCH}_{2} \mathrm{CH}_{2} \mathrm{OBn}\right), 4.05\left(3 \mathrm{H}, \mathrm{s}, \mathrm{OCH}_{3}\right), 4.57\left(2 \mathrm{H}, \mathrm{s}, \mathrm{CH}_{2} \mathrm{Ph}\right), 5.02$ $\left(2 \mathrm{H}, \mathrm{s}\right.$, pyrazol- $\left.\mathrm{CH}_{2} \mathrm{O}\right), 6.88(1 \mathrm{H}, \mathrm{d}, J=5.3 \mathrm{~Hz}, \mathrm{H}-6), 7.29-7.35(5 \mathrm{H}, \mathrm{m}, \mathrm{Ph}-$ $\mathrm{H}), 8.56(1 \mathrm{H}, \mathrm{d}, J=5.3 \mathrm{~Hz}, \mathrm{H}-5) .{ }^{13} \mathrm{C}-\mathrm{NMR}\left(50 \mathrm{MHz}, \mathrm{CDCl}_{3}\right) \delta: 23.72$ $\left(\mathrm{COCH}_{3}\right), 56.36\left(\mathrm{OCH}_{3}\right), 64.33\left(\right.$ pyrazol- $\left.\mathrm{CH}_{2} \mathrm{O}\right), 69.41\left(\mathrm{OCH}_{2} \mathrm{CH}_{2} \mathrm{OBn}\right)$, $70.73\left(\mathrm{OCH}_{2} \mathrm{CH}_{2} \mathrm{OBn}\right), 73.34\left(\mathrm{CH}_{2} \mathrm{Ph}\right), 104.98(\mathrm{C}-6), 124.83(\mathrm{C}-7 \alpha)$, $127.66\left(\mathrm{C}-4^{\prime}\right), 127.84\left(2 \times\right.$ Phenyl C), 128.43 ( $2 \times$ Phenyl C), $138.28\left(\mathrm{C}-1^{\prime}\right)$, $145.26(\mathrm{C}-3 \alpha), 148.06$ (C-3), 150.04 (C-5), $154.31(\mathrm{C}-7), 169.23\left(\mathrm{COCH}_{3}\right)$. Anal. Calcd for $\mathrm{C}_{19} \mathrm{H}_{21} \mathrm{~N}_{3} \mathrm{O}_{4}: \mathrm{C}, 64.21 ; \mathrm{H}, 5.96 ; \mathrm{N}, 11.82$. Found: $\mathrm{C}, 63.89$; $\mathrm{H}, 5.90 ; \mathrm{N}, 11.73$.

3-(2-Hydroxyethoxy)methyl-7-methoxy- $1 \mathrm{H}$-pyrazolo[4,3-b]pyridine (12) A solution of $\mathrm{BCl}_{3}(1 \mathrm{M}$ in hexane, $0.84 \mathrm{ml}, 0.84 \mathrm{mmol})$ was added dropwise under argon to a solution of $11(150 \mathrm{mg}, 0.42 \mathrm{mmol})$ in dry $\mathrm{CH}_{2} \mathrm{Cl}_{2}$ $(25 \mathrm{ml})$ at $-70^{\circ} \mathrm{C}$. The reaction mixture was stirred at $-70^{\circ} \mathrm{C}$ for $1 \mathrm{~h}$, the temperature was then raised to $-25^{\circ} \mathrm{C}$ and a cold solution of $\mathrm{CH}_{2} \mathrm{Cl}_{2} / \mathrm{MeOH}$ $(4 \mathrm{ml}, 1 / 1 \mathrm{v} / \mathrm{v})$ was added. The solvents were evaporated and the residue was purified by flash chromatography (silica gel) using a mixture of $\mathrm{CH}_{2} \mathrm{Cl}_{2} / \mathrm{MeOH}(95 / 5, \mathrm{v} / \mathrm{v})$ as the eluent to give pure $12(79.6 \mathrm{mg}, 85 \%)$ as a white solid. mp: $139-140{ }^{\circ} \mathrm{C}(\mathrm{EtOH}) .{ }^{1} \mathrm{H}-\mathrm{NMR}\left(400 \mathrm{MHz}, \mathrm{CDCl}_{3}\right) \delta$ : $3.80-3.85\left(4 \mathrm{H}, \mathrm{m}, \mathrm{OCH}_{2} \mathrm{CH}_{2} \mathrm{O}\right), 4.00\left(3 \mathrm{H}, \mathrm{s}, \mathrm{OCH}_{3}\right), 5.09(2 \mathrm{H}, \mathrm{s}$, pyrazol$\left.\mathrm{CH}_{2} \mathrm{O}\right), 6.66(1 \mathrm{H}, \mathrm{d}, J=5.4 \mathrm{~Hz}, \mathrm{H}-6), 8.42(1 \mathrm{H}, \mathrm{d}, J=5.4 \mathrm{~Hz}, \mathrm{H}-5), 11.60$ $\left(1 \mathrm{H}\right.$, br s, $\mathrm{D}_{2} \mathrm{O}$ exchang., $\left.\mathrm{NH}\right) .{ }^{13} \mathrm{C}-\mathrm{NMR}\left(50 \mathrm{MHz}, \mathrm{CDCl}_{3}\right) \delta: 56.03\left(\mathrm{OCH}_{3}\right)$, $61.54\left(\mathrm{OCH}_{2} \mathrm{CH}_{2} \mathrm{OH}\right), 65.10$ (pyrazol- $\left.\mathrm{CH}_{2} \mathrm{O}\right), 72.82\left(\mathrm{OCH}_{2} \mathrm{CH}_{2} \mathrm{OH}\right), 101.31$ (C-6), $127.18(\mathrm{C}-7 \alpha), 140.30(\mathrm{C}-3 \alpha), 143.01$ (C-3), 147.18 (C-5), 152.80 (C-7). Anal. Calcd for $\mathrm{C}_{10} \mathrm{H}_{13} \mathrm{~N}_{3} \mathrm{O}_{3}$ : C, 53.81; H, 5.87; N, 18.82. Found: C, $53.57 ; \mathrm{H}, 5.93 ; \mathrm{N}, 18.61$.

1,4-Dihydro-3-(2-hydroxyethoxy)methyl-7H-pyrazolo[4,3-b]pyridin-7one (13) A mixture of $\mathrm{HCl}(36 \%, 1 \mathrm{ml})$ in ethanol $(2 \mathrm{ml})$ was added to a solution of $12(50 \mathrm{mg}, 0.22 \mathrm{mmol})$ in ethanol $(15 \mathrm{ml})$ and the resulting solution was heated at reflux for $36 \mathrm{~h}$. The mixture was then neutralized with a saturated $\mathrm{NaHCO}_{3}$ solution, the inorganic material was filtered off, the solvents were evaporated and the residue was purified by column chromatography (silica gel) using a mixture of $\mathrm{CH}_{2} \mathrm{Cl}_{2} / \mathrm{CH}_{3} \mathrm{OH}(9 / 1, \mathrm{v} / \mathrm{v})$ as the eluent, to give $13(25 \mathrm{mg}, 54 \%)$ as a white solid. mp: $200-201{ }^{\circ} \mathrm{C}(\mathrm{EtOH}) .{ }^{1} \mathrm{H}-\mathrm{NMR}$ $\left(400 \mathrm{MHz}, \mathrm{DMSO}-d_{6}\right) \delta: 3.45-3.55\left(4 \mathrm{H}, \mathrm{m}, \mathrm{OCH}_{2} \mathrm{CH}_{2} \mathrm{O}\right), 4.69(2 \mathrm{H}, \mathrm{s}$, pyrazol- $\left.\mathrm{CH}_{2} \mathrm{O}\right), 5.94(1 \mathrm{H}, \mathrm{d}, J=7.43 \mathrm{~Hz}, \mathrm{H}-6), 7.69(1 \mathrm{H}, \mathrm{m}, \mathrm{H}-5), 11.82$ $\left(1 \mathrm{H}\right.$, br s, $\mathrm{D}_{2} \mathrm{O}$ exchang., NH-4), $13.86\left(1 \mathrm{H}\right.$, br s, $\mathrm{D}_{2} \mathrm{O}$ exchang., NH-1). ${ }^{13} \mathrm{C}-$ NMR (50 MHz, DMSO- $\left.d_{6}\right) \delta: 60.14\left(\mathrm{OCH}_{2} \mathrm{CH}_{2} \mathrm{OH}\right), 64.21\left(\right.$ pyrazol- $\left.\mathrm{CH}_{2} \mathrm{O}\right)$, $71.62\left(\mathrm{OCH}_{2} \mathrm{CH}_{2} \mathrm{OH}\right), 109.12(\mathrm{C}-6), 127.54(\mathrm{C}-3 \alpha), 133.45(\mathrm{C}-7 \alpha), 136.09$ (C-3), 137.23 (C-5), 168.55 (C-7). Anal. Calcd for $\mathrm{C}_{9} \mathrm{H}_{11} \mathrm{~N}_{3} \mathrm{O}_{3}$ : C, 51.67; H, $5.30 ; \mathrm{N}, 20.09$. Found: C, 51.36; H, 5.12; N, 19.84 .

$\mathrm{N}$-[4-(2-Benzyloxyethoxy)ethyl-2-methoxypyridin-3-yl]acetamide (20) This compound was prepared by a procedure analogous to that of $\mathbf{9}$, starting 
from $1^{16)}(700 \mathrm{mg}, 3.89 \mathrm{mmol})$, using $2.5 \mathrm{eq}$ of $n$-BuLi. The product was purified by column chromatography (silica gel) using a mixture of cyclohexane/EtOAc $(6 / 4, \mathrm{v} / \mathrm{v})$ as the eluent to provide $20(575 \mathrm{mg}, 43 \%)$ as an oil ${ }^{1} \mathrm{H}-\mathrm{NMR}\left(400 \mathrm{MHz}, \mathrm{CDCl}_{3}\right) \delta: 2.04\left(3 \mathrm{H}, \mathrm{s}, \mathrm{COCH}_{3}\right), 2.82(2 \mathrm{H}, \mathrm{t}, J=5.9 \mathrm{~Hz}$, $\left.\mathrm{PyrCH}_{2} \mathrm{CH}_{2} \mathrm{O}\right), 3.57-3.60\left(4 \mathrm{H}, \mathrm{m}, \mathrm{OCH}_{2} \mathrm{CH}_{2} \mathrm{O}\right), 3.71(2 \mathrm{H}, \mathrm{t}, J=5.9 \mathrm{~Hz}$, $\left.\mathrm{PyrCH}_{2} \mathrm{CH}_{2} \mathrm{O}\right), 3.96\left(3 \mathrm{H}, \mathrm{s}, \mathrm{OCH}_{3}\right), 4.53\left(2 \mathrm{H}, \mathrm{s}, \mathrm{CH}_{2} \mathrm{Ph}\right), 6.78(1 \mathrm{H}, \mathrm{d}, J=$ $5.1 \mathrm{~Hz}, \mathrm{H}-5), 7.28-7.35(5 \mathrm{H}, \mathrm{m}, \mathrm{Ph}-\mathrm{H}), 7.78$ (1H, br s, $\mathrm{D}_{2} \mathrm{O}$ exchang., $\left.\mathrm{NH}\right)$ $7.97(1 \mathrm{H}, \mathrm{d}, J=5.1 \mathrm{~Hz}, \mathrm{H}-6) .{ }^{13} \mathrm{C}-\mathrm{NMR}\left(50 \mathrm{MHz}, \mathrm{CDCl}_{3}\right) \delta: 23.24$ $\left(\underline{\mathrm{CH}}_{3} \mathrm{CO}\right), 32.05\left(\mathrm{Pyr}_{\mathrm{CH}} \mathrm{CH}_{2} \mathrm{O}\right), 54.05\left(\mathrm{CH}_{3} \mathrm{O}\right), 69.47\left(\mathrm{OCH}_{2} \mathrm{CH}_{2} \mathrm{O}\right), 70.09$ $\left(\mathrm{OCH}_{2} \mathrm{CH}_{2} \mathrm{O}\right), 71.41\left(\mathrm{PyrCH}_{2} \mathrm{CH}_{2} \mathrm{O}\right), 73.44\left(\mathrm{CH}_{2} \mathrm{Ph}\right), 118.15(\mathrm{C}-5), 120.36$ (C-3), 127.96 (3×Phenyl C), 128.54 (2×Phenyl C), $137.80\left(\mathrm{C}-1^{\prime}\right), 144.33$ (C-6), 147.34 (C-4), 159.67 (C-2), 169.20 ( $\left.\mathrm{CH}_{3} \mathrm{CO}\right)$. Anal. Calcd for $\mathrm{C}_{19} \mathrm{H}_{24} \mathrm{~N}_{2} \mathrm{O}_{4}$ : C, 66.22; H, 7.02; N, 8.13. Found: C, 65.97; H, 7.19; N, 8.28.

1-Acetyl-3-(2-benzyloxyethoxy)methyl-7-methoxy-1 $H$-pyrazolo[3,4clpyridine (21) This compound was prepared by a procedure analogous to that of 11, starting from $20(500 \mathrm{mg}, 1.45 \mathrm{mmol})$. The product was purified by column chromatography (silica gel) using a mixture of cyclohexane/ EtOAc $(8 / 2, \mathrm{v} / \mathrm{v})$ as the eluent to provide $21(475 \mathrm{mg}, 92 \%)$ as an oil. ${ }^{1} \mathrm{H}$ NMR $\left(400 \mathrm{MHz}, \mathrm{CDCl}_{3}\right) \delta: 2.78\left(3 \mathrm{H}, \mathrm{s}, \mathrm{COCH}_{3}\right), 3.65-3.69(2 \mathrm{H}, \mathrm{m}$, $\left.\mathrm{OCH}_{2} \mathrm{CH}_{2} \mathrm{O}\right), 3.71-3.75\left(2 \mathrm{H}, \mathrm{m}, \mathrm{OCH}_{2} \mathrm{CH}_{2} \mathrm{O}\right), 4.13\left(3 \mathrm{H}, \mathrm{s}, \mathrm{OCH}_{3}\right), 4.56$ $\left(2 \mathrm{H}, \mathrm{s}, \mathrm{CH}_{2} \mathrm{Ph}\right), 4.89\left(2 \mathrm{H}, \mathrm{s}\right.$, pyrazol- $\left.\mathrm{CH}_{2} \mathrm{O}\right), 7.30-7.34(5 \mathrm{H}, \mathrm{m}, \mathrm{Ph}-\mathrm{H})$ $7.36(1 \mathrm{H}, \mathrm{d}, J=5.5 \mathrm{~Hz}, \mathrm{H}-4), 7.99(1 \mathrm{H}, \mathrm{d}, J=5.5 \mathrm{~Hz}, \mathrm{H}-5) .{ }^{13} \mathrm{C}-\mathrm{NMR}$ $\left(50 \mathrm{MHz}, \mathrm{CDCl}_{3}\right) \delta: 24.12\left(\mathrm{COCH}_{3}\right), 54.34\left(\mathrm{OCH}_{3}\right), 66.32\left(\right.$ pyrazol- $\left.\mathrm{CH}_{2} \mathrm{O}\right)$ $69.48\left(\mathrm{OCH}_{2} \mathrm{CH}_{2} \mathrm{O}\right), 70.32\left(\mathrm{OCH}_{2} \mathrm{CH}_{2} \mathrm{O}\right), 73.45\left(\mathrm{CH}_{2} \mathrm{Ph}\right), 108.51(\mathrm{C}-4)$

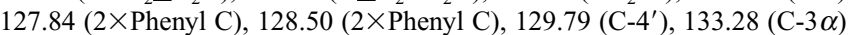
$136.22(\mathrm{C}-7 \alpha), 138.17\left(\mathrm{C}-1^{\prime}\right), 140.45$ (C-5), 147.58 (C-3), 151.77 (C-7), $168.75\left(\mathrm{COCH}_{3}\right)$. Anal. Calcd for $\mathrm{C}_{19} \mathrm{H}_{21} \mathrm{~N}_{3} \mathrm{O}_{4}: \mathrm{C}, 64.21 ; \mathrm{H}, 5.96 ; \mathrm{N}, 11.82$ Found: C, 64.33; H, 5.86; N, 11.67 .

3-(2-Hydroxyethoxy)methyl-7-methoxy-1H-pyrazolo[3,4-c]pyridine (22) This compound was prepared by a procedure analogous to that of $\mathbf{1 2}$, starting from 21 (420 mg, $1.18 \mathrm{mmol})$. The product was purified by column chromatography (silica gel) using a mixture of EtOAc/ $\mathrm{CH}_{3} \mathrm{OH}(95 / 5, \mathrm{v} / \mathrm{v})$ as the eluent to provide $22(220 \mathrm{mg}, 85 \%)$ as an amorphous solid. ${ }^{1} \mathrm{H}-\mathrm{NMR}$ $\left(400 \mathrm{MHz}, \mathrm{CDCl}_{3}\right) \delta: 2.75\left(1 \mathrm{H}\right.$, br s, $\mathrm{D}_{2} \mathrm{O}$ exchang., $\left.\mathrm{OH}\right), 3.69(2 \mathrm{H}, \mathrm{t}, J=$ $\left.4.8 \mathrm{~Hz}, \mathrm{OCH}_{2} \underline{\mathrm{CH}}_{2} \mathrm{OH}\right), 3.78\left(2 \mathrm{H}, \mathrm{t}, J=4.8 \mathrm{~Hz}, \mathrm{OCH}_{2} \mathrm{CH}_{2} \mathrm{OH}\right), 4.15(3 \mathrm{H}, \mathrm{s}$, $\left.\mathrm{OCH}_{3}\right), 4.94\left(2 \mathrm{H}, \mathrm{s}\right.$, pyrazol- $\left.\mathrm{CH}_{2} \mathrm{O}\right), 7.27(1 \mathrm{H}, \mathrm{d}, J=5.9 \mathrm{~Hz}, \mathrm{H}-4), 7.81(1 \mathrm{H}$, $\mathrm{d}, J=5.9 \mathrm{~Hz}, \mathrm{H}-5), 10.85$ (1H, br s, $\mathrm{D}_{2} \mathrm{O}$ exchang., $\left.\mathrm{NH}\right) .{ }^{13} \mathrm{C}-\mathrm{NMR}(50 \mathrm{MHz}$ $\left.\mathrm{CDCl}_{3}\right) \delta: 53.68\left(\mathrm{OCH}_{3}\right), 61.95\left(\mathrm{OCH}_{2} \mathrm{CH}_{2} \mathrm{OH}\right), 66.01\left(\right.$ pyrazol- $\left.\mathrm{CH}_{2} \mathrm{O}\right)$, $72.12\left(\mathrm{OCH}_{2} \mathrm{CH}_{2} \mathrm{OH}\right), 108.38(\mathrm{C}-4), 127.35(\mathrm{C}-3 \alpha), 128.27(\mathrm{C}-7 \alpha), 136.54$ (C-5), 143.84 (C-3), 150.76 (C-7). Anal. Calcd for $\mathrm{C}_{10} \mathrm{H}_{13} \mathrm{~N}_{3} \mathrm{O}_{3}: \mathrm{C}, 53.81 ; \mathrm{H}$, $5.87 ;$ N, 18.82. Found: C, 53.62; H, 5.79; N, 18.97 .

1,6-Dihydro-3-(2-hydroxyethoxy)methyl-7H-pyrazolo[3,4-c]pyridin-7one (23) Compound $22(50 \mathrm{mg}, 0.22 \mathrm{mmol})$ was added at $0{ }^{\circ} \mathrm{C}$ to a saturated solution of $\mathrm{HCl}$ in dry methanol $(10 \mathrm{ml})$ and the resulting solution was stirred at room temperature for $18 \mathrm{~h}$. The solvent was vacuum-evaporated and the residue was purified by column chromatography (silica gel) using a mixture of $\mathrm{CH}_{2} \mathrm{Cl}_{2} / \mathrm{CH}_{3} \mathrm{OH}(95 / 5, \mathrm{v} / \mathrm{v})$ as the eluent to give $23(40 \mathrm{mg}, 85 \%)$ mp: $235^{\circ} \mathrm{C}(\mathrm{EtOH}) .{ }^{1} \mathrm{H}-\mathrm{NMR}\left(400 \mathrm{MHz}, \mathrm{DMSO}-d_{6}\right) \delta: 3.45(2 \mathrm{H}, \mathrm{t}, J=$ $\left.4.9 \mathrm{~Hz}, \mathrm{OCH}_{2} \mathrm{CH}_{2} \mathrm{OH}\right), 3.50\left(2 \mathrm{H}, \mathrm{t}, J=4.9 \mathrm{~Hz}, \mathrm{OCH}_{2} \mathrm{CH}_{2} \mathrm{OH}\right), 4.68(2 \mathrm{H}, \mathrm{s}$, pyrazol- $\left.\mathrm{CH}_{2} \mathrm{O}\right), 6.58(1 \mathrm{H}, \mathrm{d}, J=6.6 \mathrm{~Hz}, \mathrm{H}-4), 6.92(1 \mathrm{H}, \mathrm{m}, \mathrm{H}-5), 11.25(1 \mathrm{H}$, br s, $\mathrm{D}_{2} \mathrm{O}$ exchang., $\left.\mathrm{NH}-6\right), 13.88\left(1 \mathrm{H}\right.$, br s, $\mathrm{D}_{2} \mathrm{O}$ exchang., $\left.\mathrm{NH}-1\right) .{ }^{13} \mathrm{C}-\mathrm{NMR}$ $\left(50 \mathrm{MHz}, \mathrm{DMSO}-d_{6}\right) \delta: 60.20\left(\mathrm{OCH}_{2} \mathrm{CH}_{2} \mathrm{OH}\right), 64.99$ (pyrazol- $\left.\mathrm{CH}_{2} \mathrm{O}\right), 71.62$ $\left(\mathrm{OCH}_{2} \mathrm{CH}_{2} \mathrm{OH}\right), 98.44(\mathrm{C}-4), 124.03(\mathrm{C}-3 \alpha), 125.59(\mathrm{C}-5), 132.79(\mathrm{C}-7 \alpha)$, 143.32 (C-3), 154.18 (C-7). Anal. Calcd for $\mathrm{C}_{9} \mathrm{H}_{11} \mathrm{~N}_{3} \mathrm{O}_{3}$ : C, 51.67; H, 5.30; N, 20.09. Found: C, 51.41; H, 5.24; N, 19.94 .

tert-Butyl- $N$-(6-methyl-5-nitropyridin-2-yl) Carbamate (25) To a solution of the aminopicoline $\left.\mathbf{2 4}^{17}\right)(2 \mathrm{~g}, 13.07 \mathrm{mmol})$ in dry THF $(40 \mathrm{ml})$ sodium hydride $(0.78 \mathrm{~g}, 19.4 \mathrm{mmol}, 60 \%$ suspension in paraffin oil) was added under argon at $0{ }^{\circ} \mathrm{C}$ and the resulting mixture was stirred at $\mathrm{rt}$ for $2 \mathrm{~h}$ It was then cooled at $0^{\circ} \mathrm{C}$, a solution of di-tert-butyl dicarbonate $(3.3 \mathrm{ml}$, $14.38 \mathrm{mmol})$ in dry THF $(10 \mathrm{ml})$ was added dropwise and the mixture was stirred at $\mathrm{rt}$ for an additional $4 \mathrm{~h}$. The solvent was vacuum-evaporated, a solution of $\mathrm{HCl}(0.5 \mathrm{~N}, 20 \mathrm{ml})$ was added to the residue and the product was extracted with ethyl acetate. The organic extracts were dried $\left(\mathrm{Na}_{2} \mathrm{SO}_{4}\right)$ and concentrated to dryness and the residue was purified by column chromatography (silica gel) using a mixture of cyclohexane/EtOAc $(98 / 2, \mathrm{v} / \mathrm{v})$ as the eluent, to give 25 (3.15 g, 95\%). mp: $127-128^{\circ} \mathrm{C}$ (EtOAc). ${ }^{1} \mathrm{H}-\mathrm{NMR}$ $\left(400 \mathrm{MHz}, \mathrm{CDCl}_{3}\right) \delta: 1.47\left[9 \mathrm{H}, \mathrm{s},\left(\mathrm{CH}_{3}\right)_{3}\right], 2.73\left(3 \mathrm{H}, \mathrm{s}, \mathrm{CH}_{3}\right), 7.93(1 \mathrm{H}, \mathrm{d}$, $J=9.12 \mathrm{~Hz}, \mathrm{H}-3), 8.32(1 \mathrm{H}, \mathrm{d}, J=9.12 \mathrm{~Hz}, \mathrm{H}-4), 8.37\left(1 \mathrm{H}\right.$, br s, $\mathrm{D}_{2} \mathrm{O}$ exchang., $\mathrm{NH}) .{ }^{13} \mathrm{C}-\mathrm{NMR}\left(50 \mathrm{MHz}, \mathrm{CDCl}_{3}\right) \delta: 24.29\left(\mathrm{CH}_{3}\right), 28.11\left[\left(\mathrm{CH}_{3}\right)_{3}\right]$, $82.27\left[\left(\mathrm{CH}_{3}\right)_{3} \mathrm{C}\right], 109.63(\mathrm{C}-3), 135.85(\mathrm{C}-4), 140.43 \quad(\mathrm{C}-5), 151.76$ (OCONH), 154.28 (C-6), 154.34 (C-2). Anal. Calcd for $\mathrm{C}_{11} \mathrm{H}_{15} \mathrm{~N}_{3} \mathrm{O}_{4}$ : C, 52.17; H, 5.97; N, 16.59. Found: C, 52.34; H, 5.81; N, 16.38.

tert-Butyl- $\mathrm{N}$-(5-amino-6-methylpyridin-2-yl) Carbamate (26) A solu- tion of $25(2.5 \mathrm{~g}, 9.88 \mathrm{mmol})$ in dry ethanol $(40 \mathrm{ml})$ was hydrogenated in the presence of $10 \% \mathrm{Pd} / \mathrm{C}(130 \mathrm{mg})$ under a pressure of $50 \mathrm{psi}$ at $\mathrm{rt}$ for $5 \mathrm{~h}$. The solution was filtered through a celite pad to remove the catalyst and the filtrate was evaporated to dryness to give pure $9(2.18 \mathrm{~g}, 99 \%) \mathrm{mp}$ : 122 $123{ }^{\circ} \mathrm{C}\left(\mathrm{Et}_{2} \mathrm{O}\right){ }^{1} \mathrm{H}-\mathrm{NMR}\left(400 \mathrm{MHz}, \mathrm{CDCl}_{3}\right) \delta: 1.47\left[9 \mathrm{H}, \mathrm{s},\left(\mathrm{CH}_{3}\right)_{3}\right], 2.29$ $\left(3 \mathrm{H}, \mathrm{s}, \mathrm{CH}_{3}\right), 3.40\left(2 \mathrm{H}\right.$, br s, $\mathrm{D}_{2} \mathrm{O}$ exchang., $\left.\mathrm{NH}_{2}\right), 6.95(1 \mathrm{H}, \mathrm{d}, J=8.61 \mathrm{~Hz}$, $\mathrm{H}-4), 7.30\left(1 \mathrm{H}\right.$, br s, $\mathrm{D}_{2} \mathrm{O}$ exchang., $\left.\mathrm{NH}\right), 7.54(1 \mathrm{H}, \mathrm{d}, J=8.61 \mathrm{~Hz}, \mathrm{H}-3) .{ }^{13} \mathrm{C}-$ NMR $\left(50 \mathrm{MHz}, \mathrm{CDCl}_{3}\right) \delta: 19.94\left(\mathrm{CH}_{3}\right), 28.42\left[\left(\mathrm{CH}_{3}\right)_{3}\right], 80.30\left[\left(\mathrm{CH}_{3}\right)_{3} \mathrm{C}\right]$, 111.07 (C-3), 124.74 (C-4), 136.18 (C-5), 141.57 (C-6), 143.45 (C-2), $152.88(\mathrm{OCONH})$. Anal. Calcd for $\mathrm{C}_{11} \mathrm{H}_{17} \mathrm{~N}_{3} \mathrm{O}_{2}:$ C, 59.17; H, 7.67; N, 18.82 . Found: C, 58.84; H, 7.79; N, 18.97 .

tert-Butyl- $\boldsymbol{N}$-(5-acetamido-6-methylpyridin-2-yl) Carbamate (27) To a solution of $26(2 \mathrm{~g}, 8.97 \mathrm{mmol})$ in dry dichloromethane $(20 \mathrm{ml})$ acetic anhydride $(0.95 \mathrm{ml}, 10 \mathrm{mmol})$ was added and the resulting solution was stirred at $\mathrm{rt}$ for $10 \mathrm{~h}$. The solvent was vacuum-evaporated and the residue was purified by column chromatography (silica gel) using a a mixture of cyclohexane/EtOAc $(6 / 4, \mathrm{v} / \mathrm{v})$ as the eluent, to give $27(2.15 \mathrm{~g}, 91 \%) . \mathrm{mp}: 131^{\circ} \mathrm{C}$ $\left(\mathrm{Et}_{2} \mathrm{O}\right) .{ }^{1} \mathrm{H}-\mathrm{NMR}\left(400 \mathrm{MHz}, \mathrm{CDCl}_{3}\right) \delta: 1.50\left[9 \mathrm{H}, \mathrm{s},\left(\mathrm{CH}_{3}\right)_{3}\right], 2.18(3 \mathrm{H}, \mathrm{s}$, $\left.\mathrm{COCH}_{3}\right), 2.35\left(3 \mathrm{H}, \mathrm{s}, \mathrm{CH}_{3}\right), 7.00\left(1 \mathrm{H}\right.$, br s, D $\mathrm{D}_{2} \mathrm{O}$ exchang., NHAc), $7.42(1 \mathrm{H}$, br s, $\mathrm{D}_{2} \mathrm{O}$ exchang., NHBoc), $7.73(1 \mathrm{H}, \mathrm{d}, J=8.97 \mathrm{~Hz}, \mathrm{H}-3), 7.88(1 \mathrm{H}, \mathrm{d}, J=$ $8.97 \mathrm{~Hz}, \mathrm{H}-4) .{ }^{13} \mathrm{C}-\mathrm{NMR}\left(50 \mathrm{MHz}, \mathrm{CDCl}_{3}\right) \delta: 20.25\left(\mathrm{CH}_{3}\right), 23.56\left(\mathrm{CH}_{3} \mathrm{CO}\right)$, $28.25\left[\left(\mathrm{CH}_{3}\right)_{3}\right], 80.90\left[\left(\mathrm{CH}_{3}\right)_{3} \mathrm{C}\right], 109.97(\mathrm{C}-3), 126.93(\mathrm{C}-5), 135.06(\mathrm{C}-4)$, $148.68(\mathrm{C}-2), 150.51(\mathrm{C}-6), 152.54(\mathrm{OCONH}), 169.40\left(\mathrm{COCH}_{3}\right)$. Anal. Calcd for $\mathrm{C}_{13} \mathrm{H}_{19} \mathrm{~N}_{3} \mathrm{O}_{3}$ : C, 58.85; H, 7.22; N, 15.84. Found: C, 58.61; H, 7.09; N, 15.68 .

tert-Butyl- $N$-[5-acetamido-6-(2-benzyloxyethoxy)ethylpyridin-2-yl] Carbamate (28) This compound was prepared by a procedure analogous to that of 9, starting from 27 (650 mg, $2.45 \mathrm{mmol})$, using $3.3 \mathrm{eq}$ of $n$-BuLi. The anion formation was complete at $-20^{\circ} \mathrm{C}$. The product was purified by column chromatography (silica gel) using a mixture of cyclohexane/EtOAc $(7 / 3, v / v)$ as the eluent to provide $28(420 \mathrm{mg}, 40 \%)$ as an oil. ${ }^{1} \mathrm{H}-\mathrm{NMR}$ $\left(400 \mathrm{MHz}, \mathrm{CDCl}_{3}\right) \delta: 1.51\left[9 \mathrm{H}, \mathrm{s},\left(\mathrm{CH}_{3}\right)_{3}\right], 2.01\left(3 \mathrm{H}, \mathrm{s}, \mathrm{COCH}_{3}\right), 2.93(2 \mathrm{H}$, $\left.\mathrm{t}, J=5.3 \mathrm{~Hz}, \mathrm{PyrCH}_{2} \mathrm{CH}_{2} \mathrm{O}\right), 3.60-3.63\left(4 \mathrm{H}, \mathrm{m}, \mathrm{OCH}_{2} \mathrm{CH}_{2} \mathrm{O}\right), 3.80(2 \mathrm{H}, \mathrm{t}$, $\left.J=5.3 \mathrm{~Hz}, \mathrm{PyrCH}_{2} \mathrm{CH}_{2} \mathrm{O}\right), 4.50\left(2 \mathrm{H}, \mathrm{s}, \mathrm{CH}_{2} \mathrm{Ph}\right), 7.09\left(1 \mathrm{H}\right.$, br s, $\mathrm{D}_{2} \mathrm{O}$ exchang., NHBoc), 7.27-7.36 (5H, m, Ph-H), 7.77 (1H, d, J=8.6 Hz, H-3), $8.03(1 \mathrm{H}, \mathrm{d}, J=8.6 \mathrm{~Hz}, \mathrm{H}-4), 8.86\left(1 \mathrm{H}\right.$, br s, $\mathrm{D}_{2} \mathrm{O}$ exchang., NHAc). ${ }^{13} \mathrm{C}-\mathrm{NMR}\left(50 \mathrm{MHz}, \mathrm{CDCl}_{3}\right) \quad \delta: 23.94\left(\mathrm{CH}_{3} \mathrm{CO}\right), 28.42\left[\left(\mathrm{CH}_{3}\right)_{3}\right], 35.76$ $\left(\mathrm{PyrCH}_{2} \mathrm{CH}_{2} \mathrm{O}\right), \quad 69.29 \quad\left(\mathrm{OCCH}_{2} \mathrm{CH}_{2} \mathrm{O}\right), \quad 70.40 \quad\left(\mathrm{OCH}_{2} \underline{\mathrm{CH}}_{2} \mathrm{O}\right), \quad 72.09$ $\left(\mathrm{PyrCH}_{2} \mathrm{CH}_{2} \mathrm{O}\right), 73.30\left(\mathrm{CH}_{2} \mathrm{Ph}\right), 80.98\left[\left(\mathrm{CH}_{3}\right)_{3} \mathrm{C}\right], 110.72(\mathrm{C}-3), 127.84$ ( $2 \times$ Phenyl C), 128.06 (C-4'), 128.62 (2×Phenyl C), 128.88 (C-5), 134.61 (C-4), $137.73\left(\mathrm{C}-1^{\prime}\right), 147.95$ (C-2), 150.37 (C-6), 152.36 (OCONH), 169.04 $\left(\mathrm{CH}_{3}\right.$ CO). Anal. Calcd for $\mathrm{C}_{23} \mathrm{H}_{31} \mathrm{~N}_{3} \mathrm{O}_{5}: \mathrm{C}, 64.32 ; \mathrm{H}, 7.27 ; \mathrm{N}, 9.78$. Found: C, 64.21; H, 7.23; N, 9.60.

tert-Butyl- $N$-[1-acetyl-3-(2-benzyloxyethoxy)methyl-1 $H$-pyrazolo[4,3b]pyridin-5-yl] Carbamate (29) This compound was prepared by a procedure analogous to that of 11, starting from 28 (400 $\mathrm{mg}, 0.93 \mathrm{mmol}$ ). The product was purified by column chromatography (silica gel) using a mixture of cyclohexane/EtOAc (7/3, v/v) as the eluent to provide $29(370 \mathrm{mg}, 90 \%)$ as an oil. ${ }^{1} \mathrm{H}-\mathrm{NMR}\left(400 \mathrm{MHz}, \mathrm{CDCl}_{3}\right) \delta: 1.53\left[9 \mathrm{H}, \mathrm{s},\left(\mathrm{CH}_{3}\right)_{3}\right], 2.76(3 \mathrm{H}, \mathrm{s}$, $\left.\mathrm{COCH}_{3}\right), 3.68\left(2 \mathrm{H}, \mathrm{t}, J=4.7 \mathrm{~Hz}, \mathrm{OCH}_{2} \mathrm{CH}_{2} \mathrm{O}\right), 3.83(2 \mathrm{H}, \mathrm{t}, J=4.7 \mathrm{~Hz}$, $\left.\mathrm{OCH}_{2} \mathrm{CH}_{2} \mathrm{O}\right), 4.56\left(2 \mathrm{H}, \mathrm{s}, \mathrm{CH}_{2} \mathrm{Ph}\right), 4.93\left(2 \mathrm{H}, \mathrm{s}\right.$, pyrazol- $\left.\mathrm{CH}_{2} \mathrm{O}\right), 7.27-7.34$ $(5 \mathrm{H}, \mathrm{m}, \mathrm{Ph}-\mathrm{H}), 7.49\left(1 \mathrm{H}\right.$, br s, $\mathrm{D}_{2} \mathrm{O}$ exchang., $\left.\mathrm{NH}\right), 8.23(1 \mathrm{H}, \mathrm{d}, J=9.2 \mathrm{~Hz}$, $\mathrm{H}-6), 8.61(1 \mathrm{H}, \mathrm{d}, J=9.2 \mathrm{~Hz}, \mathrm{H}-7) .{ }^{13} \mathrm{C}-\mathrm{NMR}\left(50 \mathrm{MHz}, \mathrm{CDCl}_{3}\right) \delta: 22.43$ $\left(\mathrm{COCH}_{3}\right), 28.35\left[\left(\underline{\mathrm{CH}}_{3}\right)_{3} \mathrm{C}\right], 64.30\left(\right.$ pyrazol- $\left.\mathrm{CH}_{2} \mathrm{O}\right), 69.48\left(\mathrm{OCH}_{2} \underline{\mathrm{CH}}_{2} \mathrm{O}\right)$, $70.62\left(\mathrm{OCH}_{2} \mathrm{CH}_{2} \mathrm{O}\right), 73.37\left(\mathrm{CH}_{2} \mathrm{Ph}\right), 81.50\left[\left(\mathrm{CH}_{3}\right)_{3} \mathrm{C}\right], 114.02(\mathrm{C}-6), 125.60$ (C-7), 127.81 ( $3 \times$ Phenyl C), 128.47 ( $2 \times$ Phenyl C), $130.82(\mathrm{C}-7 \alpha), 138.28$ $\left(\mathrm{C}-1^{\prime}\right), 140.67(\mathrm{C}-3 \alpha), 147.69$ (C-3), 150.74 (C-5), 152.43 (OCONH), $170.95\left(\mathrm{COCH}_{3}\right)$. Anal. Calcd for $\mathrm{C}_{23} \mathrm{H}_{28} \mathrm{~N}_{4} \mathrm{O}_{5}: \mathrm{C}, 62.71 ; \mathrm{H}, 6.41 ; \mathrm{N}, 12.72$. Found: C, 62.58; H, 6.36; N, 12.57 .

1-Acetyl-3-(2-benzyloxyethoxy)methyl-1H-pyrazolo[4,3-b]pyridin-5yl-amine (30) Trifluoroacetic acid $(0.1 \mathrm{ml}, 1.28 \mathrm{mmol})$ was added at $0{ }^{\circ} \mathrm{C}$ to a solution of $29(60 \mathrm{mg}, 0.14 \mathrm{mmol})$ in dry dichloromethane $(10 \mathrm{ml})$ and the mixture was stirred at $\mathrm{rt}$ for $10 \mathrm{~h}$. The solvent was vacuum-evaporated and the residue was treated with a saturated $\mathrm{NaHCO}_{3}$ solution and dichloromethane. The organic layer was dried $\left(\mathrm{Na}_{2} \mathrm{SO}_{4}\right)$ and concentrated to dryness. The residue was purified by flash chromatography (silica gel) using a mixture of cyclohexane/EtOAc $(1 / 1, \mathrm{v} / \mathrm{v})$ as the eluent to give $\mathbf{3 0}(45 \mathrm{mg}$, 97\%). mp: $103^{\circ} \mathrm{C}$ (EtOAc). ${ }^{1} \mathrm{H}-\mathrm{NMR}\left(400 \mathrm{MHz}, \mathrm{CDCl}_{3}\right) \delta: 2.72(3 \mathrm{H}, \mathrm{s}$, $\left.\mathrm{COCH}_{3}\right), 3.71\left(2 \mathrm{H}, \mathrm{t}, J=4.7 \mathrm{~Hz}, \mathrm{OCH}_{2} \underline{\mathrm{CH}}_{2} \mathrm{O}\right), 3.83(2 \mathrm{H}, \mathrm{t}, J=4.7 \mathrm{~Hz}$, $\left.\mathrm{OCH}_{2} \mathrm{CH}_{2} \mathrm{O}\right), 4.57\left(2 \mathrm{H}, \mathrm{s}, \mathrm{CH}_{2} \mathrm{Ph}\right), 4.87\left(2 \mathrm{H}, \mathrm{s}\right.$, pyrazol- $\left.\mathrm{CH}_{2} \mathrm{O}\right), 5.55(2 \mathrm{H}$, brs, $\mathrm{D}_{2} \mathrm{O}$ exchang., $\left.\mathrm{NH}_{2}\right), 6.45(1 \mathrm{H}, \mathrm{d}, J=9 \mathrm{~Hz}, \mathrm{H}-6), 7.28-7.36(5 \mathrm{H}, \mathrm{m}$, $\mathrm{Ph}-\mathrm{H}), 8.28(1 \mathrm{H}, \mathrm{d}, J=9 \mathrm{~Hz}, \mathrm{H}-7) .{ }^{13} \mathrm{C}-\mathrm{NMR}\left(50 \mathrm{MHz}, \mathrm{CDCl}_{3}\right) \delta: 22.36$ $\left(\mathrm{CO} \underline{C H}_{3}\right), 64.41$ (pyrazol- $\left.\mathrm{CH}_{2} \mathrm{O}\right), 69.63\left(\mathrm{OCH}_{2} \underline{\mathrm{CH}}_{2} \mathrm{O}\right), 70.51\left(\mathrm{O}_{\underline{C}} \mathrm{CH}_{2} \mathrm{O}\right)$, $73.48\left(\mathrm{CH}_{2} \mathrm{Ph}\right), 112.11(\mathrm{C}-6), 125.78(\mathrm{C}-7), 127.81\left(\mathrm{C}-4^{\prime}\right), 127.99(2 \times$ 
Phenyl C), 128.54 (2×Phenyl C), 128.91 (C-7 $\alpha), 138.17\left(\mathrm{C}-1^{\prime}\right), 141.04$ (C$3 \alpha), 147.03(\mathrm{C}-3), 157.80(\mathrm{C}-5), 170.92\left(\mathrm{COCH}_{3}\right)$. Anal. Calcd for $\mathrm{C}_{18} \mathrm{H}_{20} \mathrm{~N}_{4} \mathrm{O}_{3}$ : C, 63.52; H, 5.92; N, 16.46. Found: C, 63.34; H, 6.15; N, 16.63 .

3-(2-Hydroxyethoxy)methyl-1 $H$-pyrazolo[4,3-b]pyridin-5-yl-amine (31) This compound was prepared by a procedure analogous to that of $\mathbf{1 2}$, starting from $30(40 \mathrm{mg}, 0.12 \mathrm{mmol})$ using $5 \mathrm{eq}$ of $\mathrm{BCl}_{3}$. The product was purified by column chromatography (silica gel) using a mixture of $\mathrm{CH}_{2} \mathrm{Cl}_{2}$ / $\mathrm{CH}_{3} \mathrm{OH}(95 / 5, \mathrm{v} / \mathrm{v})$ as the eluent to provide $31(20 \mathrm{mg}, 82 \%)$. mp: $146-148^{\circ} \mathrm{C}$ (EtOH). ${ }^{1} \mathrm{H}-\mathrm{NMR}\left(400 \mathrm{MHz}, \mathrm{DMSO}-d_{6}\right) \delta: 3.48(4 \mathrm{H}, \mathrm{m}$, $\left.\mathrm{OCH}_{2} \mathrm{CH}_{2} \mathrm{O}\right), 4.63\left(2 \mathrm{H}\right.$, s, pyrazol- $\left.\mathrm{CH}_{2} \mathrm{O}\right), 4.72\left(1 \mathrm{H}\right.$, brs, $\mathrm{D}_{2} \mathrm{O}$ exchang., $\mathrm{OH}), 5.95\left(2 \mathrm{H}\right.$, br s, $\mathrm{D}_{2} \mathrm{O}$ exchang., $\left.\mathrm{NH}_{2}\right), 6.60(1 \mathrm{H}, \mathrm{d}, J=8.9 \mathrm{~Hz}, \mathrm{H}-6), 7.62$ $(1 \mathrm{H}, \mathrm{d}, J=8.9 \mathrm{~Hz}, \mathrm{H}-7), 12.78\left(1 \mathrm{H}\right.$, br s, $\mathrm{D}_{2} \mathrm{O}$ exchang., NH-1). ${ }^{13} \mathrm{C}-\mathrm{NMR}$ $\left(\mathrm{DMSO}-d_{6}\right) \quad \delta: 60.09 \quad\left(\mathrm{OCH}_{2} \mathrm{CH}_{2}-\mathrm{OH}\right), 63.24 \quad\left(\right.$ pyrazol- $\left.\mathrm{CH}_{2} \mathrm{O}\right), \quad 71.40$ $\left(\mathrm{OCH}_{2} \mathrm{CH}_{2} \mathrm{OH}\right), 110.99$ (C-6), 120.77 (C-7), 129.07 (C-7 $\left.\alpha\right), 136.91(\mathrm{C}-3 \alpha)$, 138.71 (C-3), 156.31 (C-5). Anal. Calcd for $\mathrm{C}_{9} \mathrm{H}_{12} \mathrm{~N}_{4} \mathrm{O}_{2}$ : C, 51.92; H, 5.81; N, 26.91. Found: C, 52.17; H, 5.76; N, 26.82.

tert-Butyl- $N$-(4-methyl-5-nitropyridin-2-yl) Carbamate (33) This compound was prepared by a procedure analogous to that of $\mathbf{2 5}$, starting from $\mathbf{3 2}^{18)}$ ( $\left.3 \mathrm{~g}, 19.6 \mathrm{mmol}\right)$. The product was purified by column chromatography (silica gel) using a mixture of cyclohexane/EtOAc $(4: 6, \mathrm{v} / \mathrm{v})$ as the eluent, to give pure $33(4.71 \mathrm{~g}, 95 \%)$. mp: $186{ }^{\circ} \mathrm{C}\left(\mathrm{Et}_{2} \mathrm{O} / n\right.$-pentane $) ;{ }^{1} \mathrm{H}$ NMR $\left(400 \mathrm{MHz}, \mathrm{CDCl}_{3}\right) \delta: 1.59\left[9 \mathrm{H}, \mathrm{s},\left(\mathrm{CH}_{3}\right)_{3}\right], 2.69\left(3 \mathrm{H}, \mathrm{s}, \mathrm{CH}_{3}\right), 8.10$ (1H, s, H-3), $9.12(1 \mathrm{H}, \mathrm{s}, \mathrm{H}-6), 10.43\left(1 \mathrm{H}\right.$, br s, $\mathrm{D}_{2} \mathrm{O}$ exchang., $\left.\mathrm{NH}\right) .{ }^{13} \mathrm{C}-$ NMR $\left(50 \mathrm{MHz}, \mathrm{CDCl}_{3}\right) \quad \delta: 21.59 \quad\left(\mathrm{CH}_{3}\right), 28.42 \quad\left[\left(\mathrm{CH}_{3}\right)_{3} \mathrm{CO}\right], 82.74$ $\left[\left(\mathrm{CH}_{3}\right)_{3} \mathrm{C}\right], 114.39(\mathrm{C}-3), 140.71(\mathrm{C}-5), 146.00(\mathrm{C}-6), 147.02(\mathrm{C}-4), 152.35$ (OCONH), 155.87 (C-2). Anal. Calcd for $\mathrm{C}_{11} \mathrm{H}_{15} \mathrm{~N}_{3} \mathrm{O}_{4}: \mathrm{C}, 52.17 ; \mathrm{H}, 5.97 ; \mathrm{N}$, 16.59. Found: C, 52.34; H, 5.81; N, 16.38.

tert-Butyl- $\mathrm{N}$-(5-amino-4-methylpyridin-2-yl) Carbamate (34) A solution of $\mathbf{3 3}(1 \mathrm{~g}, 3.95 \mathrm{mmol})$ in dry ethanol $(40 \mathrm{ml})$ was hydrogenated in the presence of $10 \% \mathrm{Pd} / \mathrm{C}(130 \mathrm{mg})$ under a pressure of $50 \mathrm{psi}$ at $\mathrm{rt}$ for $5 \mathrm{~h}$. The solution was filtered through a celite pad to remove the catalyst and the filtrate was evaporated to dryness to give pure 34 ( $880 \mathrm{mg}, 98 \%)$. mp: $167{ }^{\circ} \mathrm{C}\left(\right.$ EtOAc); ${ }^{1} \mathrm{H}-\mathrm{NMR}\left(400 \mathrm{MHz}, \mathrm{CDCl}_{3}\right) \delta: 1.50\left[9 \mathrm{H}, \mathrm{s},\left(\mathrm{CH}_{3}\right)_{3}\right], 2.14$ $\left(3 \mathrm{H}, \mathrm{s}, \mathrm{CH}_{3}\right), 3.34\left(2 \mathrm{H}\right.$, br s, $\mathrm{D}_{2} \mathrm{O}$ exchang., $\left.\mathrm{NH}_{2}\right), 7.69(1 \mathrm{H}, \mathrm{s}, \mathrm{H}-3), 7.78$ $(1 \mathrm{H}, \mathrm{s}, \mathrm{H}-6), 9.28\left(1 \mathrm{H}\right.$, brs, $\mathrm{D}_{2} \mathrm{O}$ exchang., $\left.\mathrm{NH}\right) .{ }^{13} \mathrm{C}-\mathrm{NMR}(50 \mathrm{MHz}$, $\left.\mathrm{CDCl}_{3}\right) \delta: 17.38\left(\mathrm{CH}_{3}\right), 28.47\left[\left(\underline{\mathrm{CH}}_{3}\right)_{3} \mathrm{C}\right], 80.08\left[\left(\mathrm{CH}_{3}\right)_{3} \underline{\mathrm{C}}\right], 114.01(\mathrm{C}-3)$, 133.86 (C-6), 134.49 (C-5), 136.96 (C-4), 145.25 (C-2), 153.26 (OCONH). Anal. Calcd for $\mathrm{C}_{11} \mathrm{H}_{17} \mathrm{~N}_{3} \mathrm{O}_{2}$ : C, 59.17; H, 7.67; N, 18.82. Found: C, 58.84; $\mathrm{H}, 7.79 ; \mathrm{N}, 18.97$.

tert-Butyl- $\mathrm{N}$-(5-acetamido-4-methylpyridin-2-yl) Carbamate (35) To a solution of $\mathbf{3 4}(880 \mathrm{mg}, 3.95 \mathrm{mmol})$ in dry dichloromethane $(20 \mathrm{ml})$ acetic anhydride $(0.56 \mathrm{ml}, 5.93 \mathrm{mmol})$ was added and the resulting solution was stirred at $\mathrm{rt}$ for $12 \mathrm{~h}$. The solvent was vacuum-evaporated and the residue was triturated with diethyl ether to give pure $35(0.98 \mathrm{~g}, 93 \%)$. mp: 208 $210^{\circ} \mathrm{C}$ (EtOAc); ${ }^{1} \mathrm{H}-\mathrm{NMR}\left(400 \mathrm{MHz}, \mathrm{DMSO}-d_{6}\right) \delta: 1.46\left[9 \mathrm{H}, \mathrm{s},\left(\mathrm{CH}_{3}\right)_{3}\right]$, $2.05\left(3 \mathrm{H}, \mathrm{s}, \mathrm{COCH}_{3}\right), 2.19\left(3 \mathrm{H}, \mathrm{s}, \mathrm{CH}_{3}\right), 7.69(1 \mathrm{H}, \mathrm{s}, \mathrm{H}-3), 8.15(1 \mathrm{H}, \mathrm{s}, \mathrm{H}-$ 6), $9.43\left(1 \mathrm{H}\right.$, brs, $\mathrm{D}_{2} \mathrm{O}$ exchang., NHAc), 9.83 (1H, br s, $\mathrm{D}_{2} \mathrm{O}$ exchang., NHBoc). ${ }^{13} \mathrm{C}-\mathrm{NMR}\left(50 \mathrm{MHz}, \mathrm{DMSO}-d_{6}\right) \delta: 17.95\left(\mathrm{CH}_{3}\right), 23.02\left(\mathrm{CH}_{3} \mathrm{CO}\right)$, $28.09\left[\left(\mathrm{CH}_{3}\right)_{3} \mathrm{C}\right], 79.65\left[\left(\mathrm{CH}_{3}\right)_{3} \mathrm{C}\right], 113.22(\mathrm{C}-3), 128.70(\mathrm{C}-5), 143.78(\mathrm{C}-$ 4), 144.55 (C-6), 149.62 (C-2), 152.80 (OCONH), $168.85\left(\underline{C O C H}_{3}\right)$. Anal. Calcd for $\mathrm{C}_{13} \mathrm{H}_{19} \mathrm{~N}_{3} \mathrm{O}_{3}$ : C, 58.85; H, 7.22; N, 15.84. Found: C, 58.61; H, 7.09; N, 15.68 .

3-tert-Butyl- $\mathrm{N}$-[5-acetamido-4-(2-benzyloxyethoxy)ethylpyridin-2-yl] Carbamate (36) This compound was prepared by a procedure analogous to that of 9, starting from $35(600 \mathrm{mg}, 2.26 \mathrm{mmol})$, using $3.3 \mathrm{eq}$ of $n$-BuLi. The anion formation was complete at $-20^{\circ} \mathrm{C}$. The product was purified by column chromatography (silica gel) using a mixture of cyclohexane/EtOAc $(1 / 1, \mathrm{v} / \mathrm{v})$ as the eluent to provide $36(390 \mathrm{mg}, 40 \%)$ as an oil. ${ }^{1} \mathrm{H}-\mathrm{NMR}$ $\left(400 \mathrm{MHz}, \mathrm{CDCl}_{3}\right) \delta: 1.51\left[9 \mathrm{H}, \mathrm{s},\left(\mathrm{CH}_{3}\right)_{3}\right], 1.99\left(3 \mathrm{H}, \mathrm{s}, \mathrm{COCH}_{3}\right), 2.82(2 \mathrm{H}$, $\left.\mathrm{t}, J=5.2 \mathrm{~Hz}, \mathrm{PyrCH}_{2} \mathrm{CH}_{2} \mathrm{O}\right), 3.56-3.59\left(4 \mathrm{H}, \mathrm{m}, \mathrm{OCH}_{2} \mathrm{CH}_{2} \mathrm{O}\right), 3.73(2 \mathrm{H}, \mathrm{t}$, $\left.J=5.2 \mathrm{~Hz}, \mathrm{PyrCH}_{2} \mathrm{CH}_{2} \mathrm{O}\right), 4.49\left(2 \mathrm{H}, \mathrm{s}, \mathrm{CH}_{2} \mathrm{Ph}\right), 7.23-7.36(5 \mathrm{H}, \mathrm{m}, \mathrm{Ph}-\mathrm{H})$, $7.81(1 \mathrm{H}, \mathrm{s}, \mathrm{H}-3), 8.41$ (1H, br s, $\mathrm{D}_{2} \mathrm{O}$ exchang., NHBoc), $8.58(1 \mathrm{H}, \mathrm{s}, \mathrm{H}-6)$, $8.75\left(1 \mathrm{H}\right.$, br s, $\mathrm{D}_{2} \mathrm{O}$ exchang., NHAc). ${ }^{13} \mathrm{C}-\mathrm{NMR}\left(50 \mathrm{MHz}, \mathrm{CDCl}_{3}\right) \delta: 23.78$ $\left(\underline{\mathrm{CH}}_{3} \mathrm{CO}\right), 28.43\left[\left(\mathrm{CH}_{3}\right)_{3} \mathrm{C}\right], 33.37\left(\mathrm{PyrCH}_{2} \mathrm{CH}_{2} \mathrm{O}\right), 69.21\left(\mathrm{OCH}_{2} \mathrm{CH}_{2} \mathrm{O}\right)$, $70.39 \quad\left(\mathrm{OCH}_{2} \mathrm{CH}_{2} \mathrm{O}\right), \quad 72.60 \quad\left(\mathrm{PyrCH}_{2} \underline{\mathrm{CH}}_{2} \mathrm{O}\right), \quad 73.32 \quad\left(\mathrm{CH}_{2} \mathrm{Ph}\right), 81.04$ $\left[\left(\mathrm{CH}_{3}\right)_{3} \mathrm{C}\right], 112.97(\mathrm{C}-3), 127.87\left(2 \times\right.$ Phenyl C), $128.08\left(\mathrm{C}-4^{\prime}\right), 128.63(2 \times$ Phenyl C), 129.39 (C-5), 137.68 (C-1' ), 144.07 (C-4), 144.54 (C-6), 148.95 (C-2), $152.78(\mathrm{OCONH}), 169.08\left(\mathrm{CH}_{3} \underline{\mathrm{CO}}\right)$. Anal. Calcd for $\mathrm{C}_{23} \mathrm{H}_{31} \mathrm{~N}_{3} \mathrm{O}_{5}: \mathrm{C}$, 64.32; H, 7.27; N, 9.78. Found: C, 64.41; H, 7.19; N, 9.93.

tert-Butyl- $N$-[1-acetyl-3-(2-benzyloxyethoxy)methyl-1 $H$-pyrazolo[3,4c]pyridin-5-yl] Carbamate (37) This compound was prepared by a procedure analogous to that of 11, starting from $36(350 \mathrm{mg}, 0.82 \mathrm{mmol})$. The product was purified by column chromatography (silica gel) using a mixture of cyclohexane/EtOAc (95/5, v/v) as the eluent to provide $37(315 \mathrm{mg}, 88 \%)$ as an amorphous solid. ${ }^{1} \mathrm{H}-\mathrm{NMR}\left(400 \mathrm{MHz}, \mathrm{CDCl}_{3}\right) \delta: 1.55\left[9 \mathrm{H}, \mathrm{s},\left(\mathrm{CH}_{3}\right)_{3}\right]$, $2.75\left(3 \mathrm{H}, \mathrm{s}, \mathrm{COCH}_{3}\right), 3.71\left(2 \mathrm{H}, \mathrm{t}, J=4.7 \mathrm{~Hz}, \mathrm{OCH}_{2} \underline{\mathrm{CH}}_{2} \mathrm{OBn}\right), 3.79(2 \mathrm{H}, \mathrm{t}$ $\left.J=4.7 \mathrm{~Hz}, \mathrm{OCH}_{2} \mathrm{CH}_{2} \mathrm{OBn}\right), 4.59\left(2 \mathrm{H}, \mathrm{s}, \mathrm{CH}_{2} \mathrm{Ph}\right), 4.92(2 \mathrm{H}, \mathrm{s}$, pyrazol$\left.\mathrm{CH}_{2} \mathrm{O}\right), 7.31-7.35$ ( $\left.5 \mathrm{H}, \mathrm{m}, \mathrm{Ph}-\mathrm{H}\right), 8.25$ (1H, br s, $\mathrm{D}_{2} \mathrm{O}$ exchang., $\left.\mathrm{NH}\right), 8.37$ $(1 \mathrm{H}, \mathrm{s}, \mathrm{H}-4), 9.41$ (1H, s, H-7). ${ }^{13} \mathrm{C}-\mathrm{NMR}\left(50 \mathrm{MHz}, \mathrm{CDCl}_{3}\right) \delta: 22.61$ $\left(\mathrm{COC} \underline{H}_{3}\right), 28.48\left[\left(\underline{\mathrm{CH}}_{3}\right)_{3} \mathrm{C}\right], 65.95\left(\right.$ pyrazol- $\left.\mathrm{CH}_{2} \mathrm{O}\right), 69.52\left(\mathrm{OCH}_{2} \underline{\mathrm{CH}}_{2} \mathrm{OBn}\right)$ $70.65\left(\mathrm{OCH}_{2} \mathrm{CH}_{2} \mathrm{OBn}\right), 73.47\left(\mathrm{CH}_{2} \mathrm{Ph}\right), 81.19\left[\left(\mathrm{CH}_{3}\right)_{3} \mathrm{C}\right], 101.87(\mathrm{C}-4)$, $127.73\left(\mathrm{C}-4^{\prime}\right), 127.87$ ( $2 \times$ Phenyl C), $128.50(2 \times$ Phenyl C), $133.05(\mathrm{C}-3 \alpha)$, $133.33(\mathrm{C}-7 \alpha), 136.42$ (C-7), $138.31\left(\mathrm{C}-1^{\prime}\right), 147.65$ (C-5), 148.59 (C-3), $152.73(\mathrm{OCONH}), 170.23\left(\mathrm{COCH}_{3}\right)$. Anal. Calcd for $\mathrm{C}_{23} \mathrm{H}_{28} \mathrm{~N}_{4} \mathrm{O}_{5}: \mathrm{C}, 62.71$; H, 6.41; N, 12.72. Found: C, 62.80; H, 6.44; N, 12.77 .

1-Acetyl-3-(2-benzyloxyethoxy)methyl-1 $H$-pyrazolo[3,4-c]pyridin-5yl-amine (38) This compound was prepared by a procedure analogous to that of 30, starting from $37(260 \mathrm{mg}, 0.59 \mathrm{mmol})$. The product was purified by column chromatography (silica gel) using a mixture of cyclohexane/ EtOAc $(4 / 6, \mathrm{v} / \mathrm{v})$ as the eluent to provide $38(175 \mathrm{mg}, 87 \%) . \mathrm{mp}: 98-100^{\circ} \mathrm{C}$ (dec.) (EtOAc). ${ }^{1} \mathrm{H}-\mathrm{NMR}\left(400 \mathrm{MHz}, \mathrm{CDCl}_{3}\right) \delta: 2.69\left(3 \mathrm{H}, \mathrm{s}, \mathrm{COCH}_{3}\right)$, $3.67-3.70\left(2 \mathrm{H}, \mathrm{m}, \mathrm{OCH}_{2} \underline{\mathrm{CH}}_{2} \mathrm{OBn}\right), 3.72-3.75\left(2 \mathrm{H}, \mathrm{m}, \mathrm{OCH}_{2} \mathrm{CH}_{2} \mathrm{OBn}\right)$ $4.36\left(2 \mathrm{H}\right.$, br s, $\mathrm{D}_{2} \mathrm{O}$ exchang., $\left.\mathrm{NH}_{2}\right), 4.57\left(2 \mathrm{H}, \mathrm{s}, \mathrm{CH}_{2} \mathrm{Ph}\right), 4.86(2 \mathrm{H}$, s, pyrazol- $\left.\mathrm{CH}_{2} \mathrm{O}\right), 6.85$ (1H, s, H-4), $7.30-7.36(5 \mathrm{H}, \mathrm{m}, \mathrm{Ph}-\mathrm{H}), 9.22(1 \mathrm{H}, \mathrm{s}, \mathrm{H}-7)$ ${ }^{13} \mathrm{C}-\mathrm{NMR}\left(50 \mathrm{MHz}, \mathrm{CDCl}_{3}\right) \delta: 22.51\left(\mathrm{COCH}_{3}\right), 66.58\left(\right.$ pyrazol- $\left.\mathrm{CH}_{2} \mathrm{O}\right)$, $69.59\left(\mathrm{OCH}_{2} \mathrm{CH}_{2} \mathrm{OBn}\right), 70.32\left(\mathrm{OCH}_{2} \mathrm{CH}_{2} \mathrm{OBn}\right), 73.41\left(\mathrm{CH}_{2} \mathrm{Ph}\right), 96.60(\mathrm{C}-$ 4), 127.84 (3×Phenyl C), 128.61 ( $2 \times$ Phenyl C), $131.56(\mathrm{C}-7 \alpha), 133.72(\mathrm{C}-$ $3 \alpha), 136.63$ (C-7), 138.24 (C-1'), 147.95 (C-3), 154.71 (C-5), 169.93 $\left(\underline{\mathrm{COCH}_{3}}\right)$. Anal. Calcd for $\mathrm{C}_{18} \mathrm{H}_{20} \mathrm{~N}_{4} \mathrm{O}_{3}: \mathrm{C}, 63.52 ; \mathrm{H}, 5.92 ; \mathrm{N}, 16.46$. Found: $\mathrm{C}, 63.66 ; \mathrm{H}, 5.71 ; \mathrm{N}, 16.65$.

3-(2-Hydroxyethoxy)methyl-1 $H$-pyrazolo[3,4-c]pyridin-5-yl-amine (39) This compound was prepared by a procedure analogous to that of $\mathbf{1 2}$ starting from $38(120 \mathrm{mg}, 0.35 \mathrm{mmol})$ using $5 \mathrm{eq} \mathrm{of} \mathrm{BCl}_{3}$. The product was purified by column chromatography (silica gel) using a mixture of $\mathrm{CH}_{2} \mathrm{Cl}_{2}$. $\mathrm{CH}_{3} \mathrm{OH}(9 / 1, \mathrm{v} / \mathrm{v})$ as the eluent to provide $39(60 \mathrm{mg}, 83 \%)$ as an amorphous solid. ${ }^{1} \mathrm{H}-\mathrm{NMR}\left(400 \mathrm{MHz}, \mathrm{DMSO}-d_{6}\right) \delta: 3.44(2 \mathrm{H}, \mathrm{t}, J=4.9 \mathrm{~Hz}$, $\left.\mathrm{OCH}_{2} \mathrm{CH}_{2} \mathrm{OH}\right), 3.50\left(2 \mathrm{H}, \mathrm{t}, J=4.9 \mathrm{~Hz}, \mathrm{OCH}_{2} \mathrm{CH}_{2} \mathrm{OH}\right), 4.69(2 \mathrm{H}, \mathrm{s}$, pyrazol$\left.\mathrm{CH}_{2} \mathrm{O}\right), 5.40\left(2 \mathrm{H}\right.$, br s, $\mathrm{D}_{2} \mathrm{O}$ exchang., $\left.\mathrm{NH}_{2}\right), 6.65(1 \mathrm{H}, \mathrm{s}, \mathrm{H}-4), 8.47(1 \mathrm{H}, \mathrm{s}$, $\mathrm{H}-7), 12.98$ (1H, br s, $\mathrm{D}_{2} \mathrm{O}$ exchang., NH-1). ${ }^{13} \mathrm{C}-\mathrm{NMR}\left(50 \mathrm{MHz}, \mathrm{DMSO}-d_{6}\right)$ $\delta: 60.16\left(\mathrm{OCH}_{2} \mathrm{CH}_{2} \mathrm{OH}\right), 65.15$ (pyrazol- $\left.\mathrm{CH}_{2} \mathrm{O}\right), 71.49\left(\mathrm{OCH}_{2} \mathrm{CH}_{2} \mathrm{OH}\right)$ 92.56 (C-4), 128.99 (C-3 $\alpha), 131.97$ (C-7), 133.59 (C-7 $\alpha), 140.01$ (C-3), 152.90 (C-5). Anal. Calcd. for $\mathrm{C}_{9} \mathrm{H}_{12} \mathrm{~N}_{4} \mathrm{O}_{2}: \mathrm{C}, 51.92 ; \mathrm{H}, 5.81 ; \mathrm{N}, 26.91$. Found: C, 51.77; H, 5.60; N, 27.18

Antiviral and Cytostatic Assays Antiviral activity against vesicular stomatitis virus, HSV-1, HSV-2, Vaccinia virus, VZV and CMV in HEL cell cultures, Coxsackie B4 virus, respiratory syncytial virus, reovirus-1, Sindbis virus and Punta Toro virus in Vero and HeLa cell cultures was determined by adding virus $\left(100 \mathrm{CCID}_{50}\right)$ to confluent human cell cultures in 96-well microtiter plates. After a $1-2 \mathrm{~h}$ incubation period, residual virus was removed and the infected cells were further incubated with the medium containing different concentrations of the compounds. After incubation at $37^{\circ} \mathrm{C}$, virus-induced cytopathogenicity was monitored microscopically when the infected control cell cultures reached full cytopathicity. For the anti-HIV assays, the viruses were administered to CEM cell cultures in the presence of different dilutions of the test compounds, and virus-induced cytopathicity (syncytia formation) was microscopically recorded. Antiviral activity was expressed as the $\mathrm{EC}_{50}$ or compound concentration required to reduce virusinduced cytopathogenicity by $50 \% . \mathrm{EC}_{50}$ values were calculated from graphic plots of the percentage of cytopathogenicity as a function of concentration of the compounds.

Cytostatic activity against L1210 (murine leukemia), Molt4/C8 and CEM (human T-lymphocytes) cells were measured by adding $c a$. 50000 to 75000 cells per $200-\mu 1$ well in $100-\mu 1$ growth medium. Then, medium $(100 \mu 1)$ containing different concentrations of the test compounds were added. After 2 $3 \mathrm{~d}$ of incubation at $37^{\circ} \mathrm{C}$, the cell number was determined with a Coulter counter. The cytostatic concentration was calculated as the $\mathrm{CC}_{50}$ or the compound concentration required to reduce cell growth by $50 \%$ relative to the number of cells in the untreated controls. $\mathrm{CC}_{50}$ values were estimated from graphic plots of the number of cells (percentage of control) as a function of the concentration of the test compounds.

\section{References}

1) Elion G. B., Furman P. A., Fyfe J. A., de Miranda P., Beauchamp L., Schaeffer H. J., Proc. Natl. Acad. Sci. U.S.A., 74, 5716-5720 (1977).

2) Elion G. B., J. Med. Virol. Suppl. I, 1993, 2-6 (1993).

3) Chu C. K., Cutler S. J., J. Heterocycl. Chem., 23, 289-319 (1986).

4) Shugar D., Pharmacol. Ther., 82, 315-335 (1999). 
5) Martin J. C., Dvorak C. A., Smee D. F., Matthews T. R., Julien P. H., Verheyden J. P. H., J. Med. Chem., 26, 759-761 (1983).

6) McGavin J. K., Goa K. L., Drugs, 61, 1153-1183 (2001).

7) Hodge R., Sutton D., Boyd M. R., Harnden M. R., Jarvest R. L., Antimicrob. Agents Chemother, 33, 1765-1773 (1989).

8) Cools M., De Clercq E., Biochem. Pharmacol., 38, 1061-1067 (1989).

9) De Clercq E., Antiviral Res., 75, 1-13 (2007).

10) Kourafalos V. N., Marakos P., Pouli N., Townsend L. B., J. Org. Chem., 68, 6466-6469 (2003).

11) Kourafalos V. N., Marakos P., Pouli N., Townsend L. B., Synlett, 2002, 1479-1482 (2002).
12) Olah G. A., Arvanaghi M., Vankar Y. D., Synthesis, 8, 660-661 (1980).

13) Fischer B. E., Hodge J. E., J. Org. Chem., 29, 776-781 (1964).

14) Emerson T. R., Rees C. W., J. Chem. Soc., 1964, 2319-2325 (1964).

15) Marakos P., Pouli N., Wise D. S., Townsend L. B., Synlett, 1997, 561562 (1997).

16) Chapman D., Hurst J., J. Chem. Soc. Perkin Trans. I, 1980, 2398 2404 (1980).

17) Besly D. M., Goldberg A. A., J. Chem. Soc., 1954, 2448-2455 (1954).

18) Pino L. N., Zehrung W. S. III, J. Am. Chem. Soc., 77, 3154-3155 (1955). 